\title{
Optimization of Rhodium-Based Catalysts for Mixed Alcohol Synthesis - 2011 Progress Report
}
MA Gerber
KO Albrecht
MJ Gray
BL Rummel

October 2011

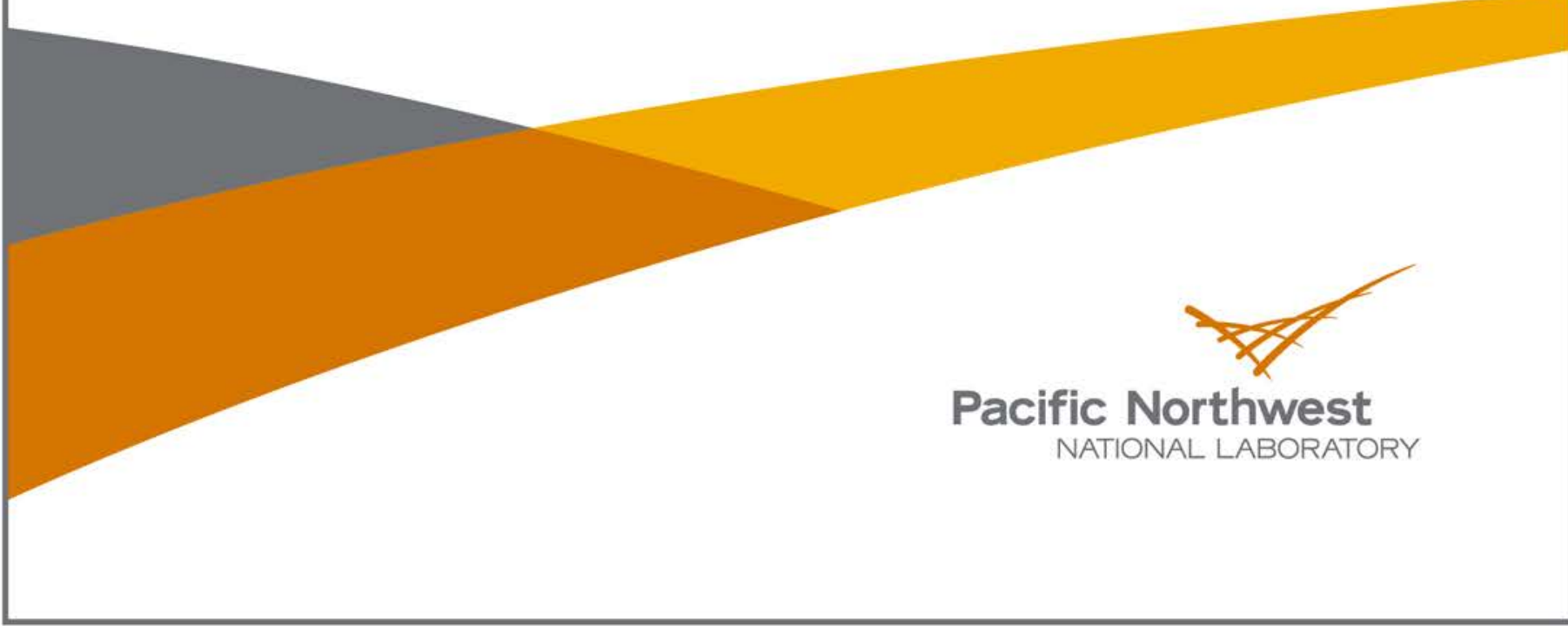




\title{
DISCLAIMER
}

This report was prepared as an account of work sponsored by an agency of the United States Government. Neither the United States Government nor any agency thereof, nor Battelle Memorial Institute, nor any of their employees, makes any warranty, express or implied, or assumes any legal liability or responsibility for the accuracy, completeness, or usefulness of any information, apparatus, product, or process disclosed, or represents that its use would not infringe privately owned rights. Reference herein to any specific commercial product, process, or service by trade name, trademark, manufacturer, or otherwise does not necessarily constitute or imply its endorsement, recommendation, or favoring by the United States Government or any agency thereof, or Battelle Memorial Institute. The views and opinions of authors expressed herein do not necessarily state or reflect those of the United States Government or any agency thereof.

\author{
PACIFIC NORTHWEST NATIONAL LABORATORY \\ operated by \\ BATTELLE \\ for the \\ UNITED STATES DEPARTMENT OF ENERGY \\ under Contract DE-AC05-76RL01830
}

Printed in the United States of America
Available to DOE and DOE contractors from the Office of Scientific and Technical Information,
P.O. Box 62, Oak Ridge, TN 37831-0062;
ph: (865) 576-8401
fax: $(865) 576-5728$
email: reports@adonis.osti.gov

\footnotetext{
Available to the public from the National Technical Information Service,

U.S. Department of Commerce, 5285 Port Royal Rd., Springfield, VA 22161

ph: (800) 553-6847

fax: (703) 605-6900

email: orders@ntis.fedworld.gov

online ordering: http://www.ntis.gov/ordering.htm
}

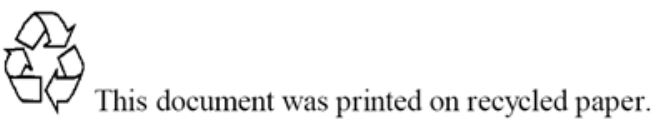

(9/2003) 


\title{
Optimization of Rhodium-Based Catalysts for Mixed Alcohol Synthesis - 2011 Progress Report
}

\author{
MA Gerber \\ KO Albrecht \\ MJ Gray \\ BL Rummel
}

October 2011

Prepared for

the U.S. Department of Energy

under Contract DE-AC05-76RL01830

Pacific Northwest National Laboratory

Richland, Washington 99352 


\section{Summary}

The U.S. Department of Energy's (DOE) Pacific Northwest National Laboratory (PNNL) has been conducting research since 2005 to develop a catalyst for the conversion of synthesis gas (carbon monoxide [CO] and hydrogen $\left[\mathrm{H}_{2}\right]$ ) into mixed alcohols for use in liquid transportation fuels. Initially, research involved screening possible catalysts based on a review of the literature, because at that time, there were no commercial catalysts available. The screening effort resulted in a decision to focus on catalysts containing rhodium (Rh) and manganese (Mn). Subsequent research has identified iridium (Ir) as a key promoter for this catalyst system.

This report summarizes research conducted during FY 2011. This research examined three main areas: 1) performance of RhMn catalysts on alternative supports, 2) optimization of Ir-promoted $\mathrm{RhMn} /$ silica $\left(\mathrm{SiO}_{2}\right)$ catalysts, and 3) evaluation of additional promoters for the RhMnIr catalysts. Research on the performance of RhMn catalysts on alternative supports examined selected zeolite supports for comparison to earlier tests in which a variety of other supports were used (Gerber 2010). In addition, tests were conducted using $\mathrm{Rh}, \mathrm{Mn}$, and Ir on selected silica and carbon supports to identify preferred supports for each class of material. Tests were also conducted to further optimize the $\mathrm{RhMnIr} / \mathrm{SiO}_{2}$ catalysts using the Davisil 645 and Merck Grade 7734 silica supports to examine compositions not previously evaluated. Finally, tests were conducted to evaluate the effects of additional promoters to the RhMnIr catalysts using the Davisil 645 silica and Hyperion CS-02C-063 multi-walled carbon nanotubes as supports.

In tests performed with four different zeolites (a ZSM-5 type and three Y-type with different $\mathrm{SiO}_{2}$ :alumina $\left[\mathrm{Al}_{2} \mathrm{O}_{3}\right]$ ratios), none performed satisfactorily in terms of either $\mathrm{C}_{2}+$ oxygenate space-timeyield (STY) or selectivity. Several tests were conducted with baseline concentrations of Rh, Mn, and Ir on several silicas that were previously tested with just Rh and Mn. Most of the tests, however, involved two impregnations to add the metals to the supports, with Rh and Mn added in the first impregnation and Ir in the second. There was considerable data scatter in duplicate tests using these "double-impregnated" catalysts so making comparisons was difficult. In spite of this issue, it appears that the Merck Grade 60 silica support and its replacement, Merck Grade 7734 silica, warrants further investigation because both achieved significantly higher converted carbon selectivities to $\mathrm{C}_{2}+$ oxygenates than the other silica supports, with one of the double-impregnated Merck Grade 60 supports also achieving a relatively high $\mathrm{C}_{2}+$ oxygenate STY. It also appears that the double-impregnated RhMnIr/Norpro 61138 silica has a relatively high $\mathrm{C}_{2}+$ oxygenate STY and selectivity relative to the other supports and could warrant further testing. At this time, the Davisil 645 silica appears to consistently provide the best overall performance among the silicas tested to date.

Tests also were conducted on the RhMnIr/carbon catalyst system using four alternative carbon supports for comparison to earlier tests performed using the Hyperion CS-02C-063 multi-walled carbon nanotube support. While all of the supported catalysts had comparable selectivities at the same operating conditions, the Hyperion CS-07C-063 carbon nanotube support and the Timrex Timcal 300 high-surfacearea graphite had significantly higher STYs than those achieved with the Hyperion CS-02C-063 carbon support. Furthermore, their STYs were significantly higher than those achieved with the Davisil 645 silica at the same conditions, while attaining slightly higher carbon selectivities to $\mathrm{C}_{2}+$ oxygenates, albeit using higher concentrations of metals on the catalysts. 
Catalyst optimization studies continued in FY 2011 using the Davisil 645 silica to further examine the optimization of the Ir-promoted RhMn catalysts, with both co-impregnated and double-impregnated catalysts. The research also was expanded to include the Merck Grade 7734 silica support because of the high selectivities to $\mathrm{C}_{2}+$ oxygenates that were achieved in earlier tests. Most of the tests used doubleimpregnated catalysts, again making comparisons difficult because of scatter in the data of duplicate tests. However, there did appear to be a consistent trend with both supports whereby increasing the concentrations of all three metals, while maintaining the baseline Rh:Mn:Ir atomic ratio of 1:0.57:0.1, significantly improved the STYs while maintaining the converted carbon selectivities to $\mathrm{C}_{2}+$ oxygenates. No beneficial trends resulted from increasing only the Ir, or both the Mn and Ir concentrations simultaneously. However, further testing with catalysts prepared with single impregnations of all three metals is warranted to more confidently understand the trends.

Research was initiated in FY 2011, using the both Davisil 645 silica and Hyperion CS-02C-063 carbon supports, to evaluate the potential for further improving catalyst performance, through the addition of one or two additional metals as promoters to the catalysts containing Rh, Mn, and Ir, with all metals added in a single impregnation. Based on the tests conducted to date, adding magnesium (Mg), at a Rh:Mg atomic ratio of about 33:1, to the Davisil 645 silica-supported RhMnIr catalyst resulted in 38\% improvement in both the $\mathrm{C}_{2}+$ oxygenate STY and converted carbon selectivity, compared to those achieved by the unpromoted catalyst. Lanthanum (La), vanadium (V), or platinum (Pt) added at comparable atomic ratios also showed significant improvements, although not as pronounced as the Mg. All four promoters warrant further optimization to determine the optimum Rh:M atomic ratio (M represents the metal promoter).

All of the promoters tested, using the RhMnIr catalyst supported on the Hyperion CS-02C-063 carbon support, achieved $\mathrm{C}_{2}+$ oxygenate STYs that were better than those achieved at comparable testing conditions using the unpromoted RhMnIr/carbon catalysts. However, the most noteworthy promoters, in terms of STY, were Pt and gallium (Ga), also with Rh:M atomic ratios of about 33:1. These promoters achieved $\mathrm{C}_{2}+$ oxygenate STYs that were $2.9 \mathrm{X}$ and $2.2 \mathrm{X}$ higher than the unpromoted catalyst, respectively. However, both had converted carbon selectivities to $\mathrm{C}_{2}+$ oxygenates that were a little lower than those for the unpromoted catalyst. Further examination of the tests with these promoters suggests that higher gas hourly space velocities (GHSVs) and/or lower operating temperatures could be employed to significantly improve their selectivity while still attaining superior STYs. The boron (B) promoted catalyst was also noteworthy because it attained the best combination high $\mathrm{C}_{2}+$ oxygenate STY and selectivity that were $75 \%$ and $11 \%$ greater than the unpromoted catalyst, respectively. The Mg and V individual promoters, and the combination promoters using zinc $(\mathrm{Zn})$ and either iron $(\mathrm{Fe})$, copper $(\mathrm{Cu})$, or palladium $(\mathrm{Pd})$ were also of interest because they had significantly higher STYs than the unpromoted catalyst while obtaining selectivities that were as good or slightly better than the unpromoted catalysts. When considered in conjunction with the performance of the Fe and $\mathrm{Zn}$ individually promoted catalysts, further optimization of $\mathrm{Zn}, \mathrm{Fe}, \mathrm{Cu}$, and $\mathrm{Pd}$ individually and the latter three in combination with $\mathrm{Zn}$ is warranted. 


\section{Acronyms/Abbreviations}

\begin{tabular}{|c|c|}
\hline $\mathrm{Al}_{2} \mathrm{O}_{3}$ & alumina \\
\hline $\mathrm{Au}$ & gold \\
\hline $\mathrm{Ba}$ & barium \\
\hline BET & Brunauer-Emmett-Teller \\
\hline $\mathrm{CO}$ & carbon monoxide \\
\hline $\mathrm{Cu}$ & copper \\
\hline DOE & U.S. Department of Energy \\
\hline $\mathrm{Fe}$ & iron \\
\hline FT & Fischer-Tropsch \\
\hline $\mathrm{Ga}$ & gallium \\
\hline GC & gas chromatograph \\
\hline GHSV & gas hourly space velocity \\
\hline $\mathrm{H}_{2}$ & hydrogen \\
\hline $\mathrm{HF}$ & hydrofluoric acid \\
\hline $\mathrm{HNO}_{3}$ & nitric acid \\
\hline HPLC & high-pressure liquid chromatograph \\
\hline ICP & inductively coupled plasma \\
\hline Ir & iridium \\
\hline $\mathrm{La}$ & lanthium \\
\hline $\mathrm{Li}$ & lithium \\
\hline Mo & molybdenum \\
\hline $\mathrm{Mn}$ & manganese \\
\hline $\mathrm{N}_{2}$ & nitrogen \\
\hline $\mathrm{Na}$ & sodium \\
\hline $\mathrm{NH}_{3}$ & ammonia \\
\hline Pd & palladium \\
\hline PNNL & Pacific Northwest National Laboratory \\
\hline $\mathrm{Pt}$ & platinum \\
\hline $\mathrm{Rh}$ & rhodium \\
\hline SCCM & standard cubic centimeters per minute \\
\hline $\mathrm{SiO}_{2}$ & silica \\
\hline STY & space-time-yield \\
\hline V & vanadium \\
\hline $\mathrm{Zn}$ & zinc \\
\hline
\end{tabular}





\section{Contents}

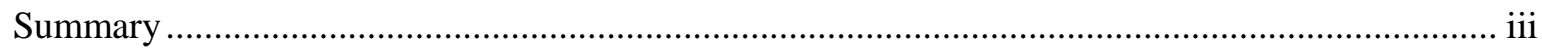

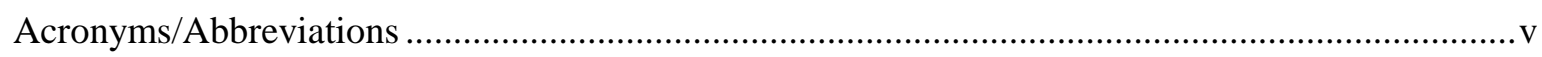

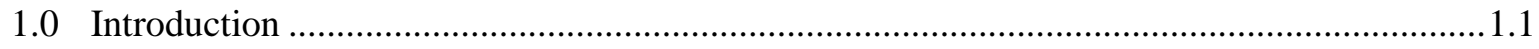

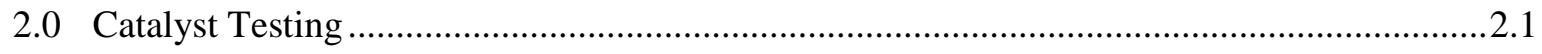

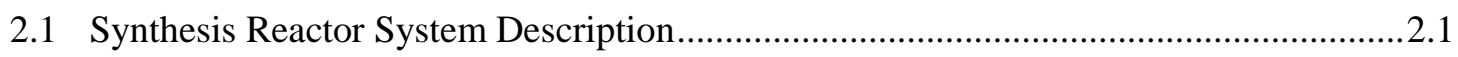

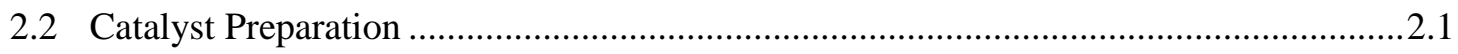

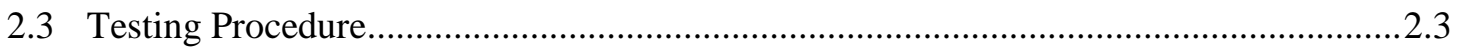

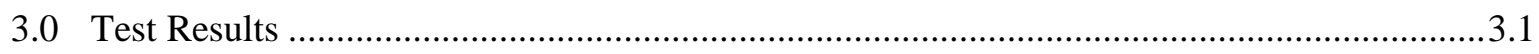

3.1 Performance of RhMn-Based Catalyst on Alternative Supports....................................... 3.1

3.1.1 Zeolite Supports .......................................................................................... 3.1

3.1.2 Silica Supports........................................................................................... 3.3

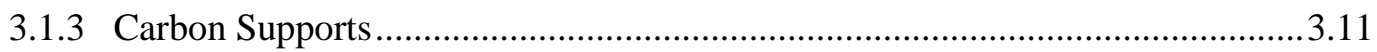

3.2 Optimization of RhMnIr/SiO2 Catalysts..................................................................... 3.14

3.2.1 Davisil 645 Silica-Supported Catalysts .............................................................14

3.2.2 Merck Grade 7734 Silica-Supported Catalysts ...................................................16

3.3 Evaluation of Promoters for the RhMnIr Catalysts ......................................................17

3.3.1 Silica-Supported Catalysts ............................................................................ 3.18

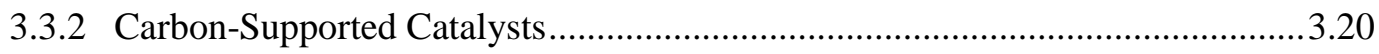

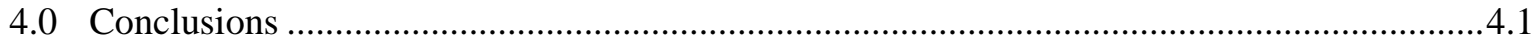

4.1 Catalyst Supports................................................................................................. 4.1

4.2 Optimization of Silica-Supported Catalysts .................................................................. 4.2

4.3 Evaluation of Promoters for the RhMnIr Catalysts .......................................................... 4.2

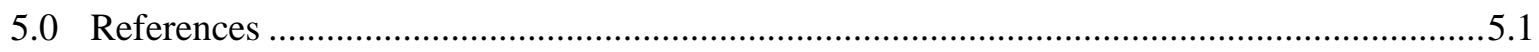




\section{Figures}

2.1 Simplified Diagram of the Reactor System Used to Test Catalysts ........................................ 2.2

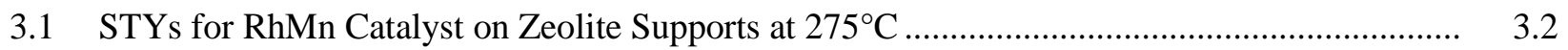

3.2 Converted Carbon Selectivity to Various Products for RhMn Catalyst on Zeolite Supports at $275^{\circ} \mathrm{C}$

3.3 Comparison of the Effect of Silica Support on $\mathrm{C}_{2}+$ Oxygenate STYs for $\mathrm{RhMn} / \mathrm{SiO}_{2}$ and $\mathrm{RhMnIr} / \mathrm{SiO}_{2}$ Catalysts at $275^{\circ} \mathrm{C}$

3.4 Comparison of the Effect of Silica Support on $\mathrm{C}_{2}+$ Oxygenate STYs for $\mathrm{RhMn} / \mathrm{SiO}_{2}$ and $\mathrm{RhMnIr} / \mathrm{SiO}_{2}$ Catalysts at $275^{\circ} \mathrm{C}$

3.5 Comparison of Trace Element Concentrations in Various Silica Supports Normalized on an Atom Basis to a Common 5.56\% Rh Concentration used in Tests with the Supports.

3.6 Comparison of the Effect of Carbon Support on $\mathrm{C}_{2}+$ oxygenate STYs for RhMnIr/Carbon Catalysts at $275^{\circ} \mathrm{C}$

3.7 Comparison of the Effect of Carbon Support on Converted Carbon Selectivities to $\mathrm{C}_{2}+$ Oxygenates for RhMnIr/Carbon Catalysts at $275^{\circ} \mathrm{C}$

3.8 Effect of Ir and Mn+ Ir Concentrations on $\mathrm{C}_{2}+$ Oxygenate STYs on Davisil 645 SilicaSupported Catalysts at $275^{\circ} \mathrm{C}$.

3.9 Effect of Ir and Mn + Ir Concentrations on Converted Carbon Selectivities to $\mathrm{C}_{2}+$ Oxygenate STYs on Davisil 645 Silica-Supported Catalysts at $275^{\circ} \mathrm{C}$

3.10 Effect of Ir and Mn+ Ir Concentrations on $\mathrm{C}_{2}+$ Oxygenate STYs on Merck Grade 7734 Silica-Supported Catalysts at $275^{\circ} \mathrm{C}$.

3.11 Effect of Ir and Mn + Ir Concentrations on Converted Carbon Selectivities to $\mathrm{C}_{2}{ }^{+}$ Oxygenate STYs on Merck Grade 7734 Silica-Supported Catalysts at $275^{\circ} \mathrm{C}$.

3.12 Effects of Different Promoters on STYs at $275^{\circ} \mathrm{C}$ 3.19

3.13 Effects of Different Promoters on Converted Carbon Selectivities at $275^{\circ} \mathrm{C}$

3.14 Comparison of the Effects of Different Promoters on the STY for the RhMnIr/Carbon Catalyst at $275^{\circ} \mathrm{C}$

3.15 Comparison of the Effects of Different Promoters on the Converted Carbon Selectivities for the RhMnIr/Carbon Catalyst at $275^{\circ} \mathrm{C}$.

\section{Tables}

3.1 Selected Properties of Zeolites used in Testing

3.2 Selected Properties of Silica Supports

3.3 Elemental Analysis Determined via ICP on the Engelhard Mod D, Davisil 645, Merck Grade 60, and Merck Grade 7734 Silicas ...

3.4 Mixed Alcohol Synthesis Silica Catalyst Supports Not Analyzed in Duplicate. 


\subsection{Introduction}

The U.S. Department of Energy's (DOE) Pacific Northwest National Laboratory (PNNL) is conducting research on the conversion of synthesis gas into mixed alcohols for use in liquid transportation fuels. This research began in 2005 with goals to identify and confirm the performance of any commercially available catalysts at that time, as part of DOE's effort to demonstrate mixed alcohol synthesis via indirect liquefaction. That effort failed to identify any commercially available catalysts although one company would offer a modified methanol synthesis catalyst for testing. In the absence of commercially available catalysts, the project was expanded to examine a variety of noncommercial catalysts and to test the most promising candidates in a bench-scale system. Potential catalysts were divided into six general classes:

- Modified methanol catalysts (copper [Cu]/zinc [Zn] and Cu/manganese [Mn] based)

- Modified molybdenum (Mo) sulfide catalysts

- Modified Mo oxide catalysts

- Rhodium (Rh)-based catalysts

- Modified Fischer-Tropsch (FT) catalysts.

Representative catalysts for each class were obtained or prepared and tested under conditions that would optimize $\mathrm{C}_{2}+$ space-time-yields (STYs) at a common operating pressure (1200 psig). Ten catalysts representative of the different catalyst classes were evaluated along with a modified methanol catalyst provided by a catalyst manufacturer in 2006 and early 2007 (Gerber et al. 2007). $C_{2}+$ oxygenate STY was the primary basis of comparison with consideration given to reasonable converted carbon selectivity to $\mathrm{C}_{2}+$ oxygenates. These criteria presupposed that nonalcoholic oxygenates could be hydrogenated further to alcohols in a subsequent step.

Only the modified FT and Rh-based catalysts achieved $\mathrm{C}_{2}+$ oxygenate STYs that were greater than $400 \mathrm{~g} / \mathrm{L}_{\text {cat }} / \mathrm{hr}$. However, FT catalysts, which were modified to improve oxygenate yields, had less than $10 \%$ carbon selectivity to $\mathrm{C}_{2}+$ oxygenates, instead, mainly producing FT liquids and hydrocarbon gases.

The two tested Rh-based catalysts, $\mathrm{Rh} / \mathrm{Mn} /$ silica $\left(\mathrm{SiO}_{2}\right)$ and $\mathrm{Rh} / \mathrm{Mn} / \mathrm{Fe} / \mathrm{SiO}_{2}$, were both very active with the latter achieving a $\mathrm{C}_{2}+$ oxygenate STY of about $400 \mathrm{~g} / \mathrm{L}_{\text {cat }} / \mathrm{hr}\left(\sim 870 \mathrm{~g} / \mathrm{kg}_{\text {cat }} / \mathrm{hr}\right)$, and an accompanying converted carbon selectivity of approximately $24 \%$ to $\mathrm{C}_{2}+$ oxygenates. This Rh catalyst also was unique because it produced very few $\mathrm{C}_{1}$ oxygenates or FT liquids. Based on these results, catalyst tests, beginning in FY 2007, focused on the silica-supported Rh-based catalyst to examine the effects of 21 other promoters besides iron (Fe) on catalyst performance. All of these catalysts used the same Rh:Mn:M atomic ratio (M represents the metal promoter) except one that used lithium (Li) as the promoter. The results of these tests identified several promoters that showed promise for improving the $\mathrm{C}_{2}+$ oxygenates STY and/or improving the selectivity of the $\mathrm{C}_{2}+$ oxygenates to alcohols (Gerber et al. 2008).

In FY 2009, the objective of the testing program shifted to optimization of the silica-supported RhMn-based catalysts that were reported by Gerber et al. (2010). Optimization involved examination of different total metals concentrations and atomic ratios of $\mathrm{Rh}$ and $\mathrm{Mn}$ as well as that of some of the more 
promising promoters identified in the earlier tests (iridium [Ir] and $\mathrm{Li}$ ). In addition, limited catalyst screening continued to examine some additional promoters that had not been tested previously.

Catalyst optimization continued during FY 2010 on further catalyst optimization and screening. During FY2010, catalyst optimization tests continued with further examination of the concentration effects of promising catalyst promoters as well as the effects of catalyst support alternatives to the Davisil 645 silica that was used in most testing up to that time (Gerber 2011). Limited testing to evaluate selected catalyst preparation techniques also were conducted in FY 2010.

This report summarizes progress made during FY 2011 to further optimize the RhMnIr catalyst. Testing of alternative catalyst supports continued in FY 2011, with an emphasis on the performance of alternative silica-support materials with the Ir-promoted $\mathrm{RhMn} / \mathrm{SiO}_{2}$ catalyst. Research continued to a limited extent on the further optimization of the catalyst composition for the silica- and carbon-supported catalysts. Research also began in FY 2011 to evaluate the effects of adding more promoters to the RhMnIr catalyst to improve converted carbon selectivity to $\mathrm{C}_{2}+$ oxygenates, while maintaining, high STYs. 


\subsection{Catalyst Testing}

\subsection{Synthesis Reactor System Description}

The bench-scale tubular reactor system used to test catalysts is designed to operate at pressures up to $1200 \mathrm{psig}$ and temperatures up to $400^{\circ} \mathrm{C}$. This system is shown in Figure 2.1. The catalyst chamber is $1.67 \mathrm{~cm}$ long and $0.635 \mathrm{~cm}$ in diameter. It usually is filled to a depth of $0.39 \mathrm{~cm}$ with porous metal frit holding the catalyst in place. A 0.159 -cm outer diameter thermocouple sheath is extended through the center of the reactor, creating an annulus-shaped catalyst chamber. Two thermocouples inside the sheath are spaced so one thermocouple is located at the center of the catalyst bed and the other just upstream. The catalyst temperature during a test is based on the thermocouple temperature at the center of the catalyst bed. The reactor is heated with hot oil to obtain better temperature control because this approach more efficiently removes the heat of reaction, thus preventing a thermal excursion when the carbon conversion is too high.

The syngas fed to the reactor is metered through a mass flow controller. The system also meters the reducing gas $\left(10 \%\right.$ hydrogen $\left[\mathrm{H}_{2}\right]$ in nitrogen $\left.\left[\mathrm{N}_{2}\right]\right)$ and $\mathrm{N}_{2}$ to the reactor during catalyst reduction. The raw product gas leaving the reactor is passed through one of two cold traps to condense liquids at $0^{\circ} \mathrm{C}$ and through a back-pressure regulator that controls the system pressure. Gas flow is redirected from one trap to the other to isolate the former trap for liquid sample recovery.

The nominal feed rate to the reactor is determined by calibrating the mass flow controllers at system pressure before the tests. A Bios DryCal flow meter located downstream of the back-pressure regulator is used for this calibration. Flow-meter readings are corrected for standard pressure and temperature. The flow meter also is used to monitor product gas flow rate downstream of the liquid sample cold traps during each test.

Dry product gas grab samples for analysis in a gas chromatograph (GC) are obtained downstream of the back-pressure regulator in a line separate from that containing the bubble flow meter, as shown in Figure 2.1. The reactor inlet, catalyst bed, cold sample trap, ambient temperature, and the upstream gas and ambient pressures are monitored during tests.

Gas cylinders containing a specified syngas mixture are used in the tests. The gas mixture consists of $\mathrm{H}_{2}$, carbon monoxide (CO), carbon dioxide $\left(\mathrm{CO}_{2}\right)$, and $\mathrm{N}_{2}$. Most of the tests conducted with the Rh-based catalysts use a gas that has a nominal $\mathrm{H}_{2}$ :CO ratio of 1.8 , with the ratio ranging from 1.7 to 1.9 . The nominal concentrations of $\mathrm{CO}_{2}$ and $\mathrm{N}_{2}$ are each $4 \%$ in the gas mixture. Variations in the $\mathrm{H}_{2}$ : $\mathrm{CO}$ ratios in the feed gas are attributed to variations in the composition of the individual gas cylinder mixtures supplied for the tests.

\subsection{Catalyst Preparation}

Catalysts tested during this portion of the testing program using inorganic supports were based on a baseline catalyst composition of 5.56\% Rh, 1.69\% Mn, and, if included, 1.03\% Ir. Carbon supported catalysts are based on the same atomic ratios but with a baseline Rh concentration of $11.7 \%$. Optimization tests using silica supports involved variations in the overall metals concentrations while maintaining the baseline atomic ratios, or maintaining the baseline concentration of Rh while, varying the Mn and Ir concentrations. 


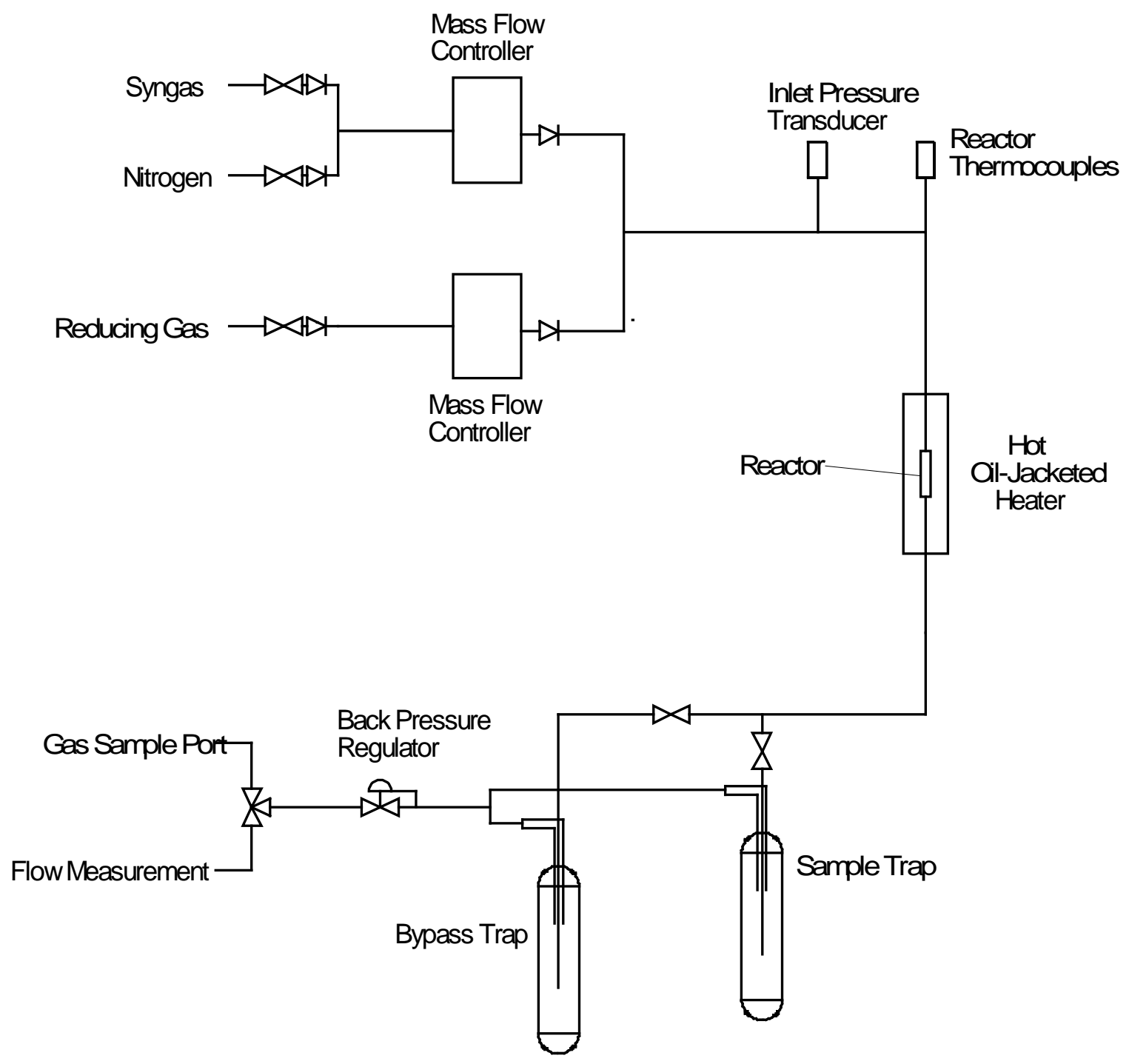

Figure 2.1. Simplified Diagram of the Reactor System Used to Test Catalysts

Most catalyst preparations consisted of a single-step impregnation procedure using the incipient wetness technique. The appropriate quantities of a rhodium nitrate solution (10 wt\% Rh concentration in solution), manganese nitrate tetrahydrate, and if used, a dihydrogen hexachloroiridium (IV) hydrate solution (14\% Ir) were combined with enough deionized water to bring the total volume of the impregnation solution to $90 \%$ of the water adsorption pore volume of the support. If additional promoters were used, they were added as soluble compounds (usually a nitrate salt) to the impregnation solution containing the other three metals.

The solution was impregnated onto the silica in drop-wise fashion on a vibrating table to keep the support solids in motion during impregnation. The impregnated catalysts were dried under an infrared lamp while being shaken until a steady weight was achieved, and then they were dried overnight at $110^{\circ} \mathrm{C}$ in a drying oven. Some of the catalysts containing $\mathrm{Rh}, \mathrm{Mn}$, and Ir in tests to optimize the metal concentrations were prepared using two impregnations with drying between impregnations to investigate the effect of the order of metal addition on catalyst performance. Each impregnation solution volume, containing the appropriate metal concentrations, was equal to the water adsorption pore volume of the 
support. The dried catalysts impregnated on inorganic supports were calcined at $400^{\circ} \mathrm{C}$ in air using a muffle furnace. Catalysts supported on carbon were not calcined prior to reduction unless otherwise noted.

Before conducting the tests, the calcined catalysts were loaded into the reactor and reduced using a $10 \% \mathrm{H}_{2}$-in- $\mathrm{N}_{2}$ gas mixture. All catalysts were heated in the reducing atmosphere to $220^{\circ} \mathrm{C}$ at $2.5^{\circ} \mathrm{C} / \mathrm{min}$ ramp-up rate and held that temperature for 1 hour, then heated from $220^{\circ} \mathrm{C}$ to $260^{\circ} \mathrm{C}$ at a rate of $1{ }^{\circ} \mathrm{C} / \mathrm{min}$ and held at that temperature for 8 hours, and finally heated to approximately $350^{\circ} \mathrm{C}$ at a rate of $1.5^{\circ} \mathrm{C} / \mathrm{min}$ and held at that temperature for 2 hours.

\subsection{Testing Procedure}

During a typical test series, a measured volume of catalyst was loaded into the reactor, and its net weight was determined. The packing density for catalyst supported on Davisil 645 and Hyperion CS02C-063 were typically $0.46 \mathrm{~g} / \mathrm{mL} \pm 10 \%$. Many of the other catalyst supports were significantly different from these values, and the basis for comparisons was catalyst weight. The reactor was placed in the reactor system, and reduced in situ at atmospheric pressure. The reactor was cooled after catalyst reduction, and the desired syngas feed rate and pressure were established. The reactor was heated slowly to a temperature at which the reaction rate was significant and maintained at that temperature for at least 24 hours to allow the catalyst to age. The product stream was directed through one of the cold traps during this time. After aging the catalyst, the product stream was redirected through the other cold trap for a period sufficient for at least 10 bed volumes of gas feed (based on the operating pressure and gas feed rate) to pass through the cold trap. This period of time provides a representative gas sample and a sufficiently large liquid sample for subsequent analysis. The operating conditions were recorded before sampling with two or more grab samples of product gas obtained and analyzed in a GC along with a feed gas sample and a calibration gas sample. The liquid recovered from the cold trap was weighed and, if two phases were present, separated into an aqueous phase and an organic phase. The weighed organic phase was not analyzed and was assumed to have a composition comparable to hexane for purposes of a carbon balance. The weighed aqueous phase was analyzed using a high-pressure liquid chromatograph (HPLC) to quantify the $\mathrm{C}_{1}-\mathrm{C}_{5}$ oxygenates, which principally were alcohols, carboxylic acids, aldehydes, esters, and any other products associated with significant peaks identified by the HPLC. After sampling, a new set of conditions (i.e., temperature and feed rate) was established, and another cold trap sample was collected at the new conditions. This procedure was repeated until a representative set of conditions was obtained to evaluate catalyst performance in terms of STY, carbon selectivity, and single-pass carbon conversion. In many cases, tests progressively advanced to higher temperatures with one or more space velocities examined during each test. In most tests, an earlier test condition was re-examined to determine whether further catalyst aging during testing affected the performance of the catalyst.

To calculate a representative average outlet flow rate during a sample collection period, a $\mathrm{N}_{2}$ balance was used with the calibrated feed flow rates. The product gas flow rate downstream of the cold trap was monitored and recorded for estimating the product gas flow rate and to provide a rough check on the accuracy of the calculated flow using a $\mathrm{N}_{2}$ balance. Carbon balances measured using this method were usually within approximately $\pm 6 \%$. 


\subsection{Test Results}

Tests were conducted in FY 2011 to further improve the RhMn catalysts. This research further examined RhMn- and Ir-promoted RhMn catalysts on selected alternative supports as well as the optimization of the concentrations of Rh, Mn, and Ir on silica and carbon supports. Tests also were performed to evaluate the effects of additional promoters on the performance of the baseline RhMnIr catalysts. The results of these tests are discussed in the following sections.

\subsection{Performance of RhMn-Based Catalyst on Alternative Supports}

Testing was continued in FY 2011 to identify any alternative supports that might have performance characteristics superior to the Davisil 645 silica or Hyperion CS-02C-063 multi-walled nanotube carbonsupported catalysts, which have served as the baseline supports for catalyst composition optimization in FY 2011 and in FY 2010. These include tests with several zeolites containing Rh and Mn, and further evaluation of selected silica and carbon supports that included Ir in the catalyst formulations.

Tests were usually conducted at sequentially higher temperatures (nominally $255^{\circ} \mathrm{C}, 275^{\circ} \mathrm{C}, 300^{\circ} \mathrm{C}$, $315^{\circ} \mathrm{C}$ and $325^{\circ} \mathrm{C}$, followed by a repeat of an earlier condition, nominally $300^{\circ} \mathrm{C}$ ) to quantify any deactivation that had occurred. The catalyst performance comparison with the different supports was made for the common test condition of $275^{\circ} \mathrm{C}$, because the Davisil 645 silica and Hyperion CS-02C-063 carbon supports had good STYs at this temperature and earlier research suggested that RhMn and RhMnIr catalysts were thermally stable at $275^{\circ} \mathrm{C}$. Comparison criteria were $\mathrm{C}_{2}+$ oxygenate STY and converted carbon selectivity to $\mathrm{C}_{2}+$ oxygenates.

\subsubsection{Zeolite Supports}

During FY 2011, four zeolites were evaluated as supports for the RhMn catalyst. Tests were conducted using the baseline concentrations of 5.56\% Rh and 1.69\% Mn (no Ir). Selected properties of each zeolite as reported by the manufacturer's literature are shown in Table 3.1. The first three zeolites are Y-type zeolites. The Zeolyst CBV100 and CBV600 zeolites have similar $\mathrm{SiO}_{2}$ :alumina $\left(\mathrm{Al}_{2} \mathrm{O}_{3}\right)$ molar ratios, but the former has a high sodium $(\mathrm{Na})$ content incorporated as the cation, while the latter does not, having an ammonium cation in place of Na. The Zeolyst CBV901 has a much higher $\mathrm{SiO}_{2}: \mathrm{Al}_{2} \mathrm{O}_{3}$ molar ratio and is in the hydrogen cation form. The Zeolyst CBV5524 zeolite is a ZSM-5 type zeolite in an ammonium cation form.

Figures 3.1 and 3.2 compare $\mathrm{C}_{2}+$ oxygenate STYs and converted carbon selectivities to various products for the RhMn catalyst on the zeolite supports at $1200 \mathrm{psig}, 275^{\circ} \mathrm{C}$ and a GHSV of $7500 \mathrm{~L} / \mathrm{L}_{\text {cat }} / \mathrm{hr}$. Also shown in these figures are the results for the Davisil 645-supported catalyst. It can be seen from Figure 3.1 that the RhMn catalyst supported on the best zeolite (Zeolyst CBV901) had a $\mathrm{C}_{2}+$ oxygenate STY that was about six times lower than the Davisil 645-supported catalyst, while the other two Y-type zeolite-supported catalysts had STYs that were less than 5\% of that for the Davisil 645 silica-supported catalyst. The difference in the activities of the Y-type-supported catalysts may be attributed to their respective concentrations of Na, as shown in Table 3.1. The ZMS-5 type zeolite had a STY that was about $70 \%$ of that for the CBV901-supported catalyst and a Na concentration that was about 2/3 greater than the Zeolyst CBV901-supported catalyst. The Zeolyst CBV901 catalyst also had the best converted 
carbon selectivity to $\mathrm{C}_{2}+$ oxygenates as shown in Figure 3.2, but this was still only about $70 \%$ of that achieved by the Davisil 645-supported catalyst. The other three supported catalysts had selectivities that were less than one-half of that achieved with the Davisil 645-supported catalyst.

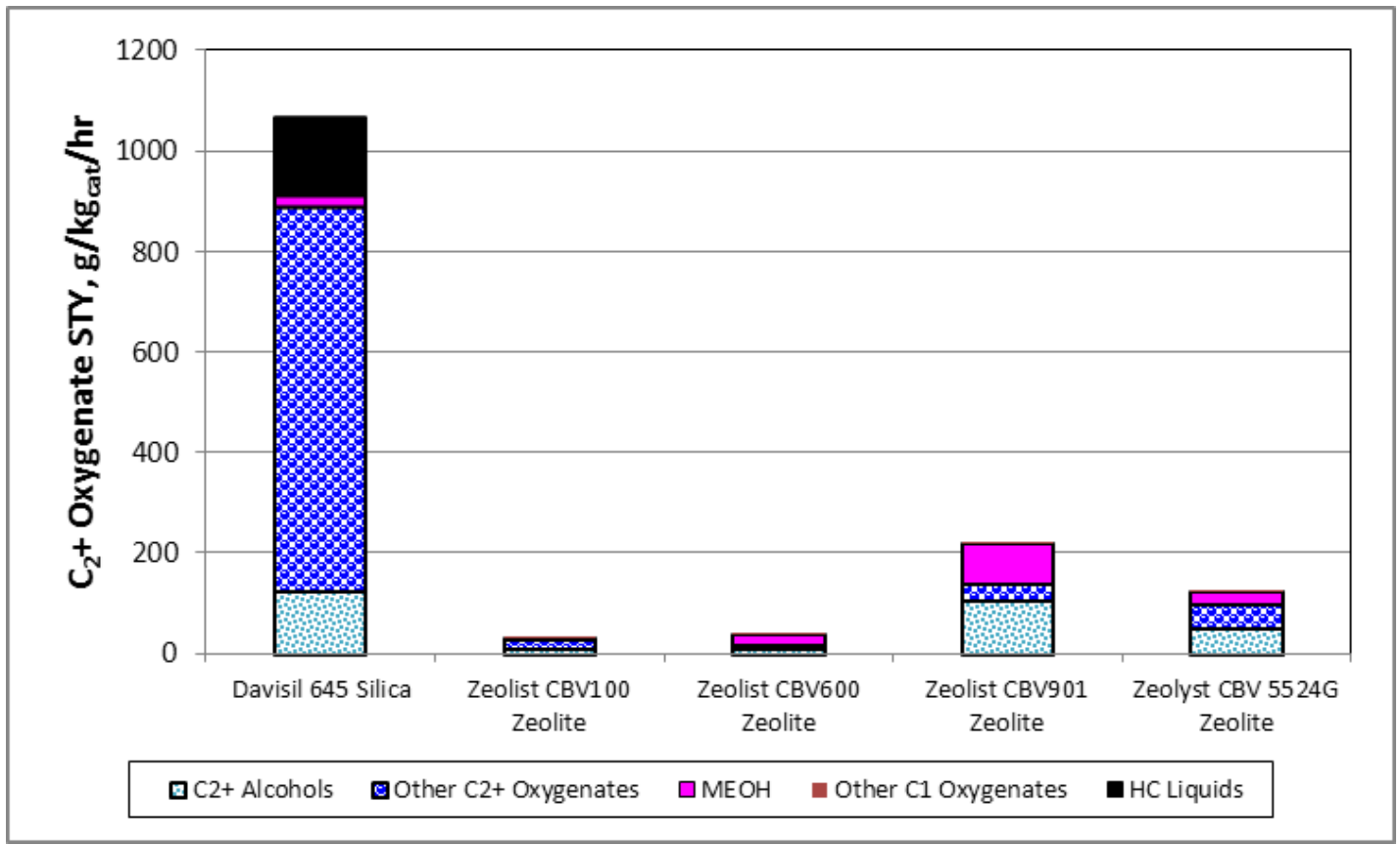

Figure 3.1. STYs for RhMn Catalyst on Zeolite Supports at $275^{\circ} \mathrm{C}$

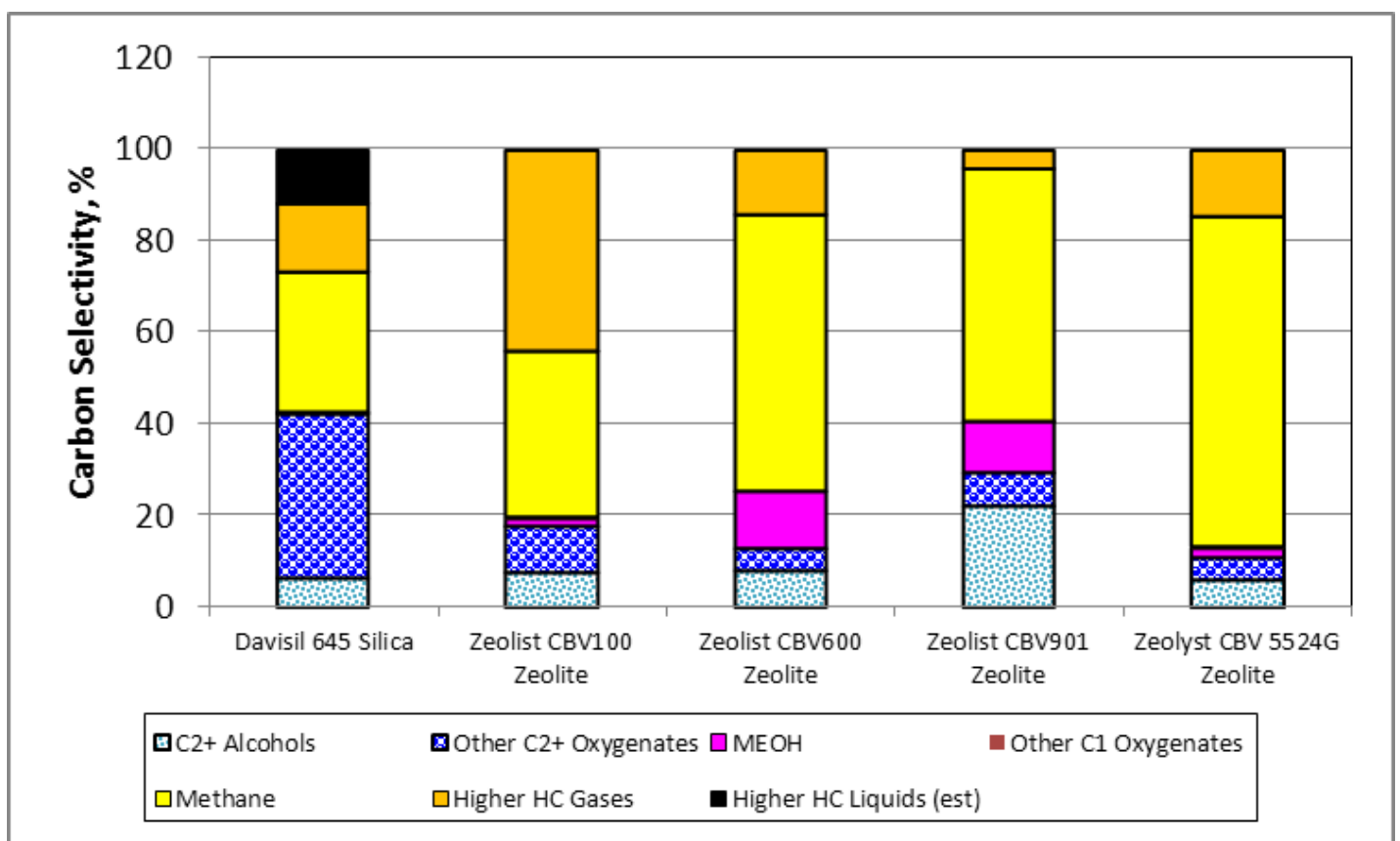

Figure 3.2. Converted Carbon Selectivity to Various Products for RhMn Catalyst on Zeolite Supports at $275^{\circ} \mathrm{C}$ 
Table 3.1. Selected Properties of Zeolites used in Testing

\begin{tabular}{|c|c|c|c|c|c|}
\hline Zeolite & $\begin{array}{l}\mathrm{SiO}_{2}: \mathrm{Al}_{2} \mathrm{O}_{3} \\
\text { Mole Ratio }\end{array}$ & $\begin{array}{c}\text { Nominal Cation } \\
\text { Form }\end{array}$ & $\begin{array}{c}\text { NaO Concentration } \\
\mathrm{Wt} \%\end{array}$ & $\begin{array}{c}\text { Unit Cell } \\
\text { Size } \AA \\
\end{array}$ & $\begin{array}{c}\text { Surface Area, } \\
\mathrm{m}^{2} / \mathrm{g}\end{array}$ \\
\hline Zeolyst CBV100 & 5.1 & Sodium & 13.0 & 24.65 & 900 \\
\hline Zeolyst CBV600 & 5.2 & Ammonium & 0.2 & 24.35 & 660 \\
\hline Zeolyst CBV901 & 80 & Hydrogen & 0.03 & 24.24 & 700 \\
\hline Zeolyst CBV5524 & 50 & Ammonium & 0.05 & NA & 400 \\
\hline
\end{tabular}

\subsubsection{Silica Supports}

Several of the alternative silicas that were tested in FY 2010 using only Rh and Mn, were further investigated in FY 2011 to evaluate their performance with the addition of Ir. These catalysts also used the baseline concentrations of $5.56 \% \mathrm{Rh}$ and $1.69 \% \mathrm{Mn}$, plus $1.03 \%$ Ir. In most cases, Ir was added in a second impregnation. The silicas that were evaluated were Davisil 645, Engelhard Mod D, Norpro SS1137, Norpro SS1138, and Sigma Aldrich Merck Grade 60. In addition, Sigma Aldrich Merck Grade 7734 was evaluated for both RhMn and RhMnIr catalysts, because it was reported to be equivalent to the Merck Grade 60 that it was replacing.

Figures 3.3 and 3.4 show the performances of silica-supported catalysts, both with and without Ir in the catalyst formulation, at common test conditions of $1200 \mathrm{psig}, 275^{\circ} \mathrm{C}$, and a GHSV of $7500 \mathrm{~L} / \mathrm{L}_{\mathrm{cat}} / \mathrm{hr}$. Several of the double-impregnated catalysts were prepared in different batches and tested to ascertain their reproducibility. Also shown in the figures are the corresponding graphs for supports containing only $\mathrm{Rh}$ and Mn.

The results are difficult to interpret at this time, because the catalysts prepared with Ir added in a second impregnation (double-impregnated catalyst) were not reproducible and not comparable to catalysts with all three metals co-impregnated on the same support. For example, two tests were performed with all three metals co-impregnated on the Davisil 645 silica support, using the same master batch of catalyst for both tests. The two catalysts had $\mathrm{C}_{2}+$ oxygenate STYs that were only about $4 \%$ different with respect to each other (810 and $777 \mathrm{~g} / \mathrm{kg}_{\text {cat }} / \mathrm{hr}$ ) as shown in Figure 3.3. Similarly, their converted carbon selectivities were within $5 \%$ of one another (47.4\% and $49.4 \%$; see Figure 3.4 ). The two doubleimpregnated catalysts used catalysts prepared from two different batches and had $\mathrm{C}_{2}+$ oxygenate STYs that were both very different from one another ( 298 and $464 \mathrm{~g} / \mathrm{kg}_{\mathrm{cat}} / \mathrm{hr}$ ) as well being much lower than the STYs for the single-impregnated catalysts STYs. The converted carbon selectivities to $\mathrm{C}_{2}+$ oxygenates were also very different from one another (33.5\% and 51.6\%), although one was comparable to the selectivities achieved by the single-impregnated catalysts.

The Merck Grade 60 catalyst was also tested using RhMnIr catalyst prepared with a single impregnation and two catalysts prepared with two impregnations in separate batches. Again, there was considerable variation in the STYs for the double impregnated RhMnIr catalysts relative to each other and to the single-impregnated catalyst on the same support. More significant, both double-impregnated catalysts had converted carbon selectivities to $\mathrm{C}_{2}+$ oxygenates that were greater than $60 \%$ (61\% and $62 \%$ ), which was about 18\% higher than the best Davisil 645 -supported RhMnIr catalyst tested at these conditions. Both double-impregnated RhMnIr catalysts also had significantly higher $\mathrm{C}_{2}+$ oxygenate STYs and converted carbon selectivities to $\mathrm{C}_{2}+$ oxygenates than either the single-impregnated RhMn or RhMnIr catalysts on the same support material. Furthermore, one of the double-impregnated RhMnIr catalysts on the Merck Grade 60 silica support had a $\mathrm{C}_{2}+$ oxygenate STY $\left(771 \mathrm{~g} / \mathrm{kg}_{\mathrm{cat}} / \mathrm{hr}\right)$ that was comparable to the STYs achieved with the single-impregnated RhMnIr catalysts on the Davisil 645 support. 


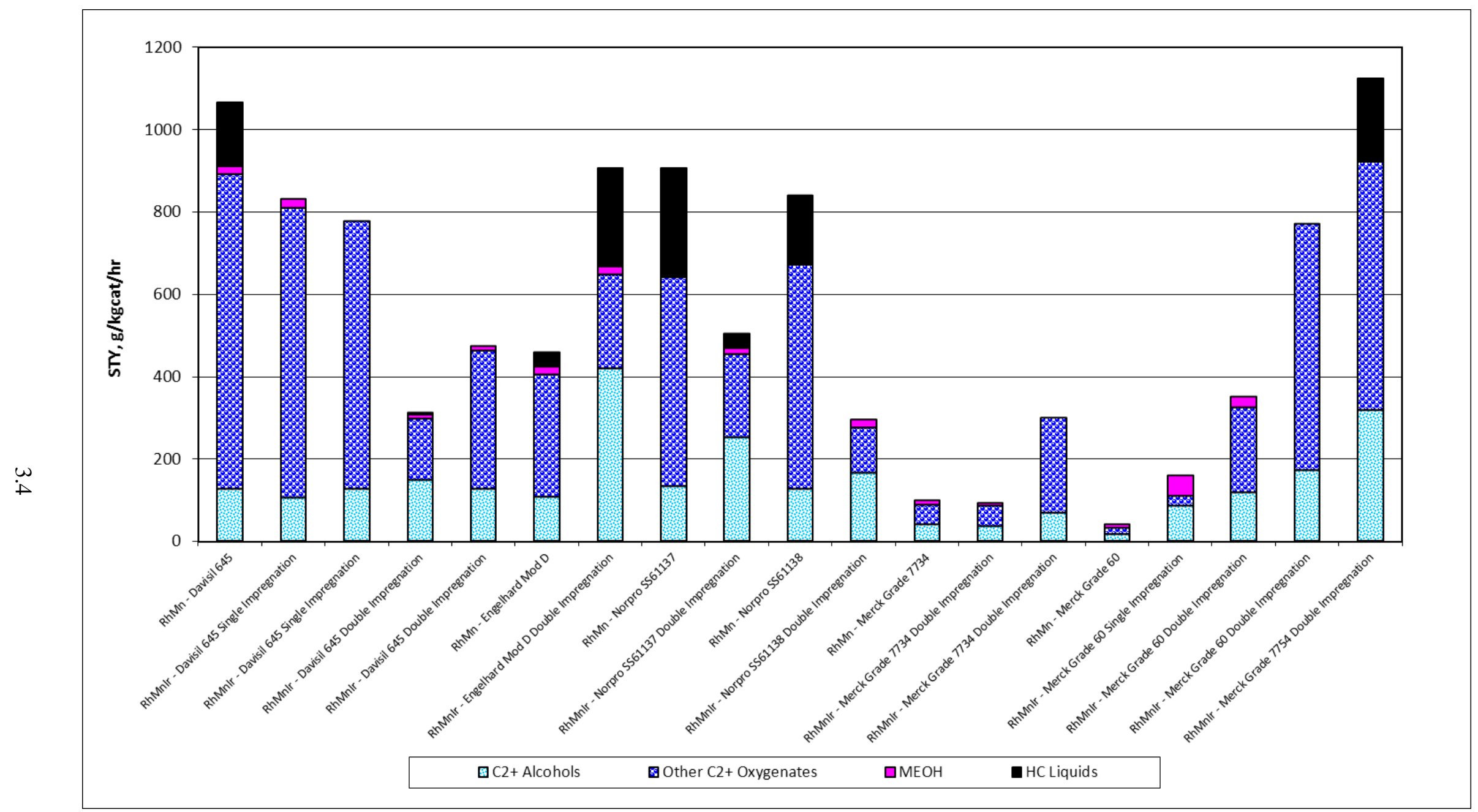

Figure 3.3. Comparison of the Effect of Silica Support on $\mathrm{C}_{2}+$ Oxygenate $\mathrm{STYs}$ for $\mathrm{RhMn} / \mathrm{SiO}_{2}$ and $\mathrm{RhMnIr} / \mathrm{SiO}{ }_{2}$ Catalysts at $275^{\circ} \mathrm{C}$ 


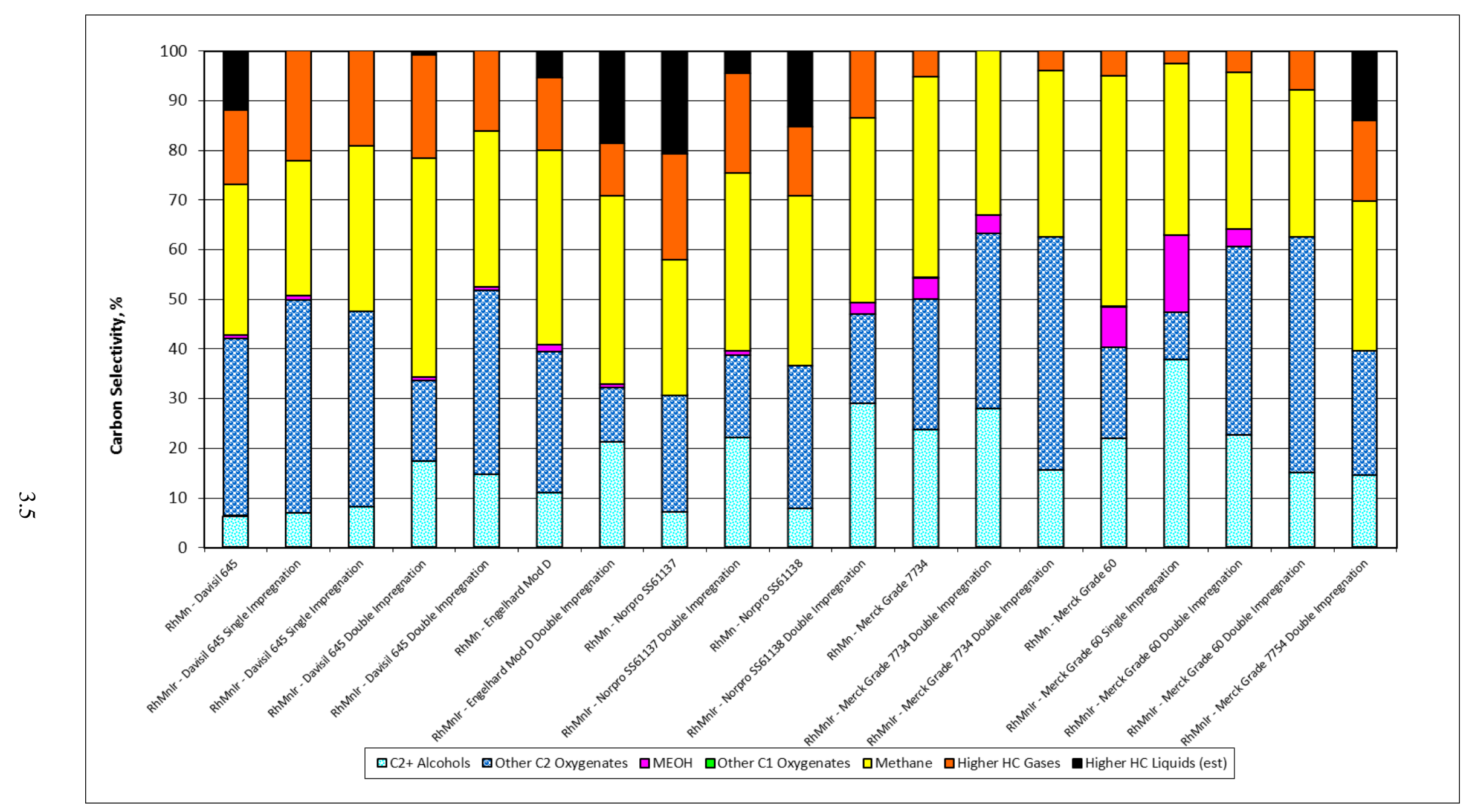

Figure 3.4. Comparison of the Effect of Silica Support on $\mathrm{C}_{2}+$ Oxygenate STYs for $\mathrm{RhMn} / \mathrm{SiO}_{2}$ and $\mathrm{RhMnIr} / \mathrm{SiO}_{2}$ Catalysts at $275^{\circ} \mathrm{C}$ 
Because one of the two double-impregnated catalysts using the Merck Grade 60 support had both a high $\mathrm{C}_{2}+$ oxygenated STY and one of the highest selectivities to $\mathrm{C}_{2}+$ oxygenates, tests were performed using the Merck Grade 7734 silica support, which is supposed to have properties that are similar to the Merck Grade 60 silica. As shown in Figure 3.3, the $\mathrm{C}_{2}+$ oxygenate STYs for the two double-impregnated RhMnIr catalysts on the Merck Grade 7734 silica support are very different from one another. One catalyst has a relatively low STY that is comparable to the RhMn catalyst (no Ir) on the same Merck Grade 7734 silica support. The other catalyst has a STY that is comparable to the catalyst prepared with the Merck Grade 60 silica support that had the lower STY. It is noteworthy that the converted carbon selectivities for both of the double-impregnated RhMnIr catalysts on the Merck Grade 7734 were also greater than $60 \%$ to $\mathrm{C}_{2}+$ oxygenates.

Taken together, the results for the Davisil 645, Merck Grade 60, and Merck Grade7734 supports, it is apparent that the double impregnated catalysts produce too much scatter to draw any firm conclusions regarding their true potential. On the other hand, the combination of high $\mathrm{C}_{2}+$ oxygenate selectivity and STY for one of the Merck Grade 60 RhMnIr double-impregnated catalysts would warrant further investigation of this catalyst preparation technique.

Comparison of the performance of the other silica supports is limited because only the doubleimpregnated RhMnIr catalysts were prepared and tested. With that qualification in mind, it appears that the double impregnated RhMnIr catalyst on the Norpro SS61138 has converted carbon selectivities to $\mathrm{C}_{2}+$ oxygenates that are generally better than the RhMnIr catalysts prepared on the Norpro SS61137 and Engelhard Mod D catalyst supports, and is fairly comparable to that achieved with any of the Davisil 645 silica-supported RhMnIr catalysts.

The tested silica catalysts were characterized to better understand the differences in catalyst performance on the different supports. The surface area, pore size distribution and pore volume of various inorganic mixed alcohol catalyst supports were probed using $\mathrm{N}_{2}$ adsorption and desorption tests performed at $-196^{\circ} \mathrm{C}$. The surface areas reported in Table 3.2 are the Brunauer-Emmett-Teller (BET) surface areas. The pore size distribution was determined using the desorption isotherm of the adsorption/ desorption hysteresis curve using the Barret-Joyner-Halenda method. It appears that none of these surface characteristics explains the differences in behaviors of the catalysts prepared on the different supports. For example, the two Merck silicas have nearly the same properties even though their STYs are very different.

Table 3.2. Selected Properties of Silica Supports

\begin{tabular}{lccccc}
\hline Support Description & Surface Area $\mathrm{m}^{2} / \mathrm{g}$ & $\begin{array}{c}\text { Micropore } \\
\text { Surface Area } \\
\mathrm{m}^{2} / \mathrm{g}\end{array}$ & $\begin{array}{c}\text { Pore } \\
\text { Volume } \\
\mathrm{cm}^{3} / \mathrm{g}\end{array}$ & $\begin{array}{c}\text { Nominal } \\
\text { Pore Size } \\
\AA^{(\mathrm{a})}\end{array}$ & $\begin{array}{c}\mathrm{NH}_{3} \text { Desorption } \\
\mu \mathrm{mol} / \mathrm{g}\end{array}$ \\
\hline Davisil 645 & 285 & 22.1 & 1.2 & $120-170$ & 30 \\
Engelhard Mod D & 583 & 30.1 & 0.33 & $20-35$ & 207 \\
Norpro SS61137 & 194 & 4 & 0.69 & $85-160$ & 24 \\
Norpro SS61138 & 276 & 14.2 & 1.04 & $100-200$ & 50 \\
Merck Grade 60 & 535 & 0 & 0.73 & $40-70$ & 21 \\
Merck Grade 7734 & 530 & 0 & 0.79 & $50-110$ & 18 \\
\hline
\end{tabular}

(a) Qualtitative determination 
The acidity of several silica mixed alcohol catalyst supports was determined by probing with ammonia $\left(\mathrm{NH}_{3}\right)$. A Micromeritics AutoChem II 2920 was utilized for the $\mathrm{NH}_{3}$ saturation and subsequent temperature programmed desorption (TPD) experiments. A Pfieffer Thermostar mass spectrometer (MS) was used to quantify the amount of $\mathrm{NH}_{3}$ that was desorbed by each sample during the TPD portion of an experiment. About $100 \mathrm{mg}$ of catalyst was loaded into a sample quartz tube. Typically, the silica sample was pretreated prior to $\mathrm{NH}_{3}$ saturation in a stream of helium (He) flowing at 25 standard cubic centimeters per minute (SCCM) at $300^{\circ} \mathrm{C}$ for 2 hours. After pretreatment, the temperature was lowered to $120^{\circ} \mathrm{C}$ while helium continued to flow. Once the sample had reached $120^{\circ} \mathrm{C}$, a stream of $15 \% \mathrm{NH}_{3} / \mathrm{He}$ was passed over the catalyst at 25 SCCM for 1 hour. Next, the gas stream was switched back to helium flowing at 25 SCCM. Helium continued to pass over the sample for 2 hours at $120^{\circ} \mathrm{C}$ to remove any physisorbed $\mathrm{NH}_{3}$. After passing helium over the sample for 2 hours, the TPD experiment was initiated. The TPD experiment consisted of ramping up the temperature of the sample from $120^{\circ} \mathrm{C}$ to $800^{\circ} \mathrm{C}$ at $10^{\circ} \mathrm{C}$ intervals in helium flowing at $25 \mathrm{SCCM}$. A 1-hour soak at $800^{\circ} \mathrm{C}$ also was employed as part of the TPD. The amount of $\mathrm{NH}_{3}$ desorbed was determined by first determining the area under the $\mathrm{m} / \mathrm{e}=$ 16 mass trace and subsequently converting the area to moles of $\mathrm{NH}_{3}$. The mass trace $\mathrm{m} / \mathrm{e}=16$ was chosen instead of the parent mass $(\mathrm{m} / \mathrm{e}=17)$ to better de-convolute the results from any background water. Conversion from area to moles of $\mathrm{NH}_{3}$ utilized an automatic calibration sequence performed by the AutoChem II 2920. Over the course of numerous calibration sequences, the calibration has been observed to vary by approximately $\pm 10 \%$.

The total quantity of $\mathrm{NH}_{3}$ desorbed per gram of support is shown in Table 3.1. This table reveals that the Davisil 645 Merck Aldrich Grade 60, Norpro 61137 and 61138 and Sigma Aldrich Grade 7734 supports all desorbed $50 \mu \mathrm{mol}$ or less of $\mathrm{NH}_{3}$ /g of support. Generally, $\mathrm{NH}_{3}$ desorption was complete below $250^{\circ} \mathrm{C}$, which indicates that the small number of acid sites present are relatively weak. A notable exception to this was the Norpro SS61138 support, which had a small number of stronger acid sites indicated by desorption of $\mathrm{NH}_{3}$ at temperatures above $\sim 300^{\circ} \mathrm{C}$. The Engelhard Mod D silica support has significantly more acid sites with a modest percentage (about $44 \%$ ) of stronger acid sites.

The silica catalyst supports were also analyzed for composition using inductively coupled plasma (ICP). To obtain quantitative results, samples had to be solubilized via acid digestion. The samples were digested in acid (1-mL hydrofluoric acid [HF]/9-mL nitric acid $\left[\mathrm{HNO}_{3}\right]$ ) in polytetrafluoroethylene microwave vessels at approximately $200^{\circ} \mathrm{C}$. After digestion in the $\mathrm{HF} / \mathrm{HNO}_{3}$ mixture, 0.5 -g boric acid was added to each vessel to complex any remaining HF. The solutions were then transferred and diluted to $50 \mathrm{~mL}$ followed by ICP analysis. To determine silica amounts, the solutions were further diluted 100 times. The Davisil 645, Engelhard Mod D, Merck Grade 60, and Merck 7734 were analyzed in duplicate, whereas single samples were analyzed for the Norpro SS1137 and SS1138 silicas. The silica catalyst supports had varying levels of water present. Thus, the silica samples were dried under vacuum for several hours, and the water loss was determined gravimetrically.

The silica samples analyzed in duplicate are reported in Table 3.3, and the single samples are reported in Table 3.4. The elements are reported as the wt\% oxides using the most stable oxidation state of each cation. In addition to the elements listed in the tables, the silica samples also were analyzed for gold ( $\mathrm{Au}$ ), barium (Ba), cadmium, cobalt, chromium, Mn, Mo, nickel, phosphorus, Pd, Pt, rhenium, tin, V, tungsten, yttrium, and Zn. However, they were not observed at the detection level of the instrument used to detect these species ( $25 \mathrm{ppm})$. 
Table 3.3. Elemental Analysis Determined via ICP on the Engelhard Mod D, Davisil 645, Merck Grade 60, and Merck Grade 7734 Silicas

\begin{tabular}{|c|c|c|c|c|c|c|c|c|}
\hline \multirow{2}{*}{$\begin{array}{c}\mathrm{Wt} \% \\
\text { Sample }\end{array}$} & \multicolumn{2}{|c|}{ Engelhard Mod D ${ }^{(a)}$} & \multicolumn{2}{|c|}{ Davisil $645^{(a)}$} & \multicolumn{2}{|c|}{ Merck Aldrich Grade 60} & \multicolumn{2}{|c|}{ Sigma Aldrich Grade 7734} \\
\hline & Primary ${ }^{(a)}$ & Duplicate $^{(a)}$ & Primary $^{(a)}$ & Duplicate $^{(\mathrm{a})}$ & Primary $^{(\mathrm{b})}$ & Duplicate $^{(\mathrm{b})}$ & Primary $^{(a)}$ & Duplicate $^{(\mathrm{b})}$ \\
\hline $\mathrm{Al}_{2} \mathrm{O}_{3}$ & 1.903 & 1.616 & 0.011 & 0.009 & 0.038 & 0.036 & 0.030 & 0.045 \\
\hline \multicolumn{9}{|l|}{$\mathrm{As}_{2} \mathrm{O}_{3}$} \\
\hline $\mathrm{CaO}$ & 0.034 & 0.032 & 0.036 & 0.035 & 0.062 & 0.057 & 0.085 & 0.126 \\
\hline $\mathrm{CuO}$ & 0.001 & 0.001 & & & & & & \\
\hline $\mathrm{Fe}_{2} \mathrm{O}_{3}$ & 0.037 & 0.039 & 0.020 & 0.020 & 0.024 & 0.021 & 0.005 & 0.008 \\
\hline $\mathrm{K}_{2} \mathrm{O}$ & 0.007 & 0.006 & 0.007 & 0.006 & 0.006 & 0.005 & & \\
\hline $\mathrm{MgO}$ & 0.124 & 0.104 & 0.008 & 0.008 & 0.010 & 0.010 & 0.014 & 0.022 \\
\hline $\mathrm{Na}_{2} \mathrm{O}$ & 0.054 & 0.055 & 0.075 & 0.070 & 0.158 & 0.162 & 0.158 & 0.218 \\
\hline \multicolumn{9}{|l|}{$\mathrm{P}_{2} \mathrm{O}_{5}$} \\
\hline $\mathrm{PbO}_{2}$ & 0.001 & 0.001 & 0.002 & 0.002 & 0.002 & 0.001 & & \\
\hline $\mathrm{SrO}$ & 0.001 & 0.001 & 0.001 & 0.001 & 0.001 & 0.001 & & \\
\hline $\mathrm{TiO}_{2}$ & 0.015 & 0.013 & 0.002 & 0.002 & 0.027 & 0.025 & 0.016 & 0.024 \\
\hline $\mathrm{SO}_{2}$ & & & & & 0.034 & 0.042 & 0.059 & 0.088 \\
\hline $\mathrm{ZrO}_{2}$ & 0.005 & 0.005 & 0.008 & 0.008 & 0.007 & 0.007 & 0.012 & 0.015 \\
\hline $\mathrm{SiO}_{2}$ & 82.0 & 79.0 & 93.3 & 88.0 & 79.3 & 63.9 & 78.2 & 74.8 \\
\hline $\mathrm{H}_{2} \mathrm{O}$ & \multicolumn{2}{|c|}{$11.8^{(\mathrm{c})}$} & \multicolumn{2}{|c|}{$2.1^{(\mathrm{c})}$} & \multicolumn{2}{|c|}{$6.1^{(\mathrm{c})}$} & \multicolumn{2}{|c|}{$4.5^{(\mathrm{d})}$} \\
\hline Total & 96.0 & 92.7 & 95.6 & 90.3 & 85.8 & 70.3 & 83.1 & 79.8 \\
\hline $\begin{array}{l}\text { (a) Sample } \\
\text { (b) Silica s } \\
\text { (c) Determ } \\
\text { (d) Determ }\end{array}$ & $\begin{array}{l}\text { completely } \\
\text { size was } \\
\text { y drying c } \\
\text { y drying }\end{array}$ & $\begin{array}{l}\text { gested such th } \\
\text { ater than what } \\
\text { sample of eac } \\
\text { ample of silic }\end{array}$ & $\begin{array}{l}\text { solids could } \\
\text { be dissolv } \\
\text { a for } 2 \text { day } \\
3 \text { days at } 1\end{array}$ & $\begin{array}{l}\text { observed mac } \\
\text { HF and solid } \\
\text { der vacuum at }\end{array}$ & $\begin{array}{l}\text { pically } \\
\text { re observed. } \\
\text { C. }\end{array}$ & & & \\
\hline
\end{tabular}


Table 3.4. Mixed Alcohol Synthesis Silica Catalyst Supports Not Analyzed in Duplicate

\begin{tabular}{ccc}
\hline $\mathrm{Wt} \%$ & Norpro SS61138 & Norpro SS61137 \\
\hline $\mathrm{Al}_{2} \mathrm{O}_{3}$ & 0.268 & 0.125 \\
$\mathrm{As}_{2} \mathrm{O}_{3}$ & & 0.001 \\
$\mathrm{CaO}$ & 0.021 & 0.032 \\
$\mathrm{CuO}$ & 0.001 & 0.001 \\
$\mathrm{Fe}_{2} \mathrm{O}_{3}$ & 0.024 & 0.027 \\
$\mathrm{~K}_{2} \mathrm{O}$ & 0.012 & 0.011 \\
$\mathrm{MgO}$ & 0.015 & 0.048 \\
$\mathrm{Na}_{2} \mathrm{O}$ & 0.102 & 0.101 \\
$\mathrm{P}_{2} \mathrm{O}_{5}$ & & \\
$\mathrm{PbO}_{2}$ & 0.002 & \\
$\mathrm{SrO}^{(a)}$ & 0.001 & 0.001 \\
$\mathrm{TiO}_{2}$ & 0.005 & 0.003 \\
$\mathrm{Au}_{2} \mathrm{O}_{3}$ & & \\
$\mathrm{SO}_{2}$ & 0.028 & \\
$\mathrm{ZrO}_{2}$ & 0.008 & 0.012 \\
$\mathrm{SiO}_{2}$ & 90.5 & 20.0 \\
$\mathrm{H}_{2} \mathrm{O}^{(\mathrm{b})}$ & 2.9 & 1.9 \\
$\mathrm{Total}$ & 93.9 & 22.2
\end{tabular}

(a) Sample was completely digested such that no solids could be observed macroscopically.

(b) Determined by drying one sample for 2 days under vacuum at $200^{\circ} \mathrm{C}$.

All of the samples digested by the method outlined above were dissolved so no solids were visible to the naked eye except for the Merck Grade 60 samples and one of the duplicated samples of the Merck Grade 7734 silica. Regarding the Merck Grade 60 samples, white, fluffy solids were still evident after the digestion. The reason that the Merck Grade 60 failed to digest to completion is unknown. Regarding the Sigma Aldrich Grade 7734 silica, a greater concentration of silica was tested than could be digested by the HF added was believed to be the cause of the incomplete digestion. It also is noteworthy that the Norpro SS61137 sample had a very poor material balance (22.3\%), presumably because of unaccounted for silica, even though no visible solids were observed following digestion. All other samples had material balances between $70.3 \%$ and $96.0 \%$.

To get an idea on the potential significance of the silica support trace elements on the Rh-based catalysts, their concentrations were compared on atomic ratio basis to the nominal $5.56 \% \mathrm{Rh}$ that was used in the catalysts tested as shown in Figure 3.5. This can, in principle, be correlated to earlier tests in which these same trace elements were added as promoter metals to the $\mathrm{RhMn} / \mathrm{SiO}_{2}$ catalyst using the Davisil 645 silica support (Gerber 2008, 2009). 


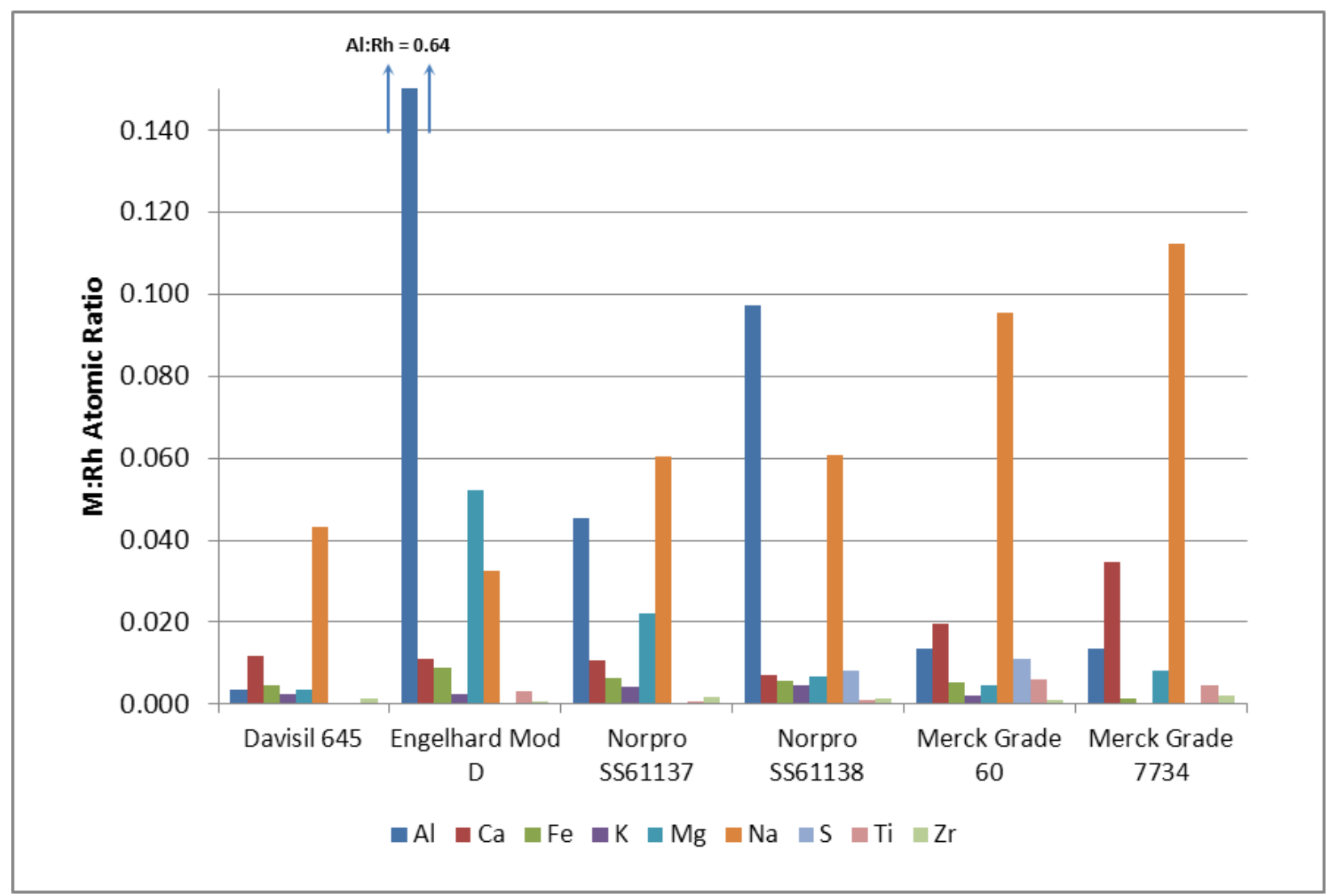

Figure 3.5. Comparison of Trace Element Concentrations in Various Silica Supports Normalized on an Atom Basis to a Common 5.56\% Rh Concentration used in Tests with the Supports

The major contaminants were aluminum, $\mathrm{Na}, \mathrm{Mg}$, and calcium. The Al:Rh ratio was significantly higher for the Engelhard Mod D, Norpro SS61138, and Norpro SS61137 silicas. However, the Al:Rh ratio was six and a half times higher in the Engelhard Mod D silica than in the Norpro SS61138 and about 14 times higher than in the Norpro SS61137 silica. Examination of the $\mathrm{NH}_{3}$ desorption data for the various supports suggests that the alumina is accountable for high $\mathrm{NH}_{3}$ adsorption in the Engelhard Mod D support and appears to be responsible for the desorption of $\mathrm{NH}_{3}$ at temperatures above $300^{\circ} \mathrm{C}$.

Sodium is a significant contaminant in all of the silica supports producing $\mathrm{Na}: \mathrm{Rh}$ atomic ratios ranging from a low of 0.033:1 to a high of 0.11:1.0. In earlier testing, a sample of the baseline $\mathrm{RhMn/Davisil} 645$ Silica was promoted by the addition of $\mathrm{Na}$ in a second impregnation at a 0.3:1 Na:Rh atomic ratio. The resulting catalyst was found to be inactive at $275^{\circ} \mathrm{C}$ and had relatively low activity at temperatures as high as $345^{\circ} \mathrm{C}\left(\mathrm{C}_{2}+\right.$ oxygenate STY of $\left.150 \mathrm{~g} / \mathrm{kg}_{\text {cat }} / \mathrm{hr}\right)$. A catalyst similarly made using Li as the promoter was moderately active at $275^{\circ} \mathrm{C}\left(\mathrm{C}_{2}+\right.$ oxygenate STY of $\left.210 \mathrm{~g} / \mathrm{kg}_{\mathrm{cat}} / \mathrm{hr}\right)$ with higher STYs achieved with lower $\mathrm{Li}: \mathrm{Rh}$ atomic ratios. From these earlier tests, it would be reasonable to expect some degree of adverse performance using the silica supports with the higher Na concentrations in terms of the $\mathrm{C}_{2}+$ oxygenate STY. However, when the Na levels for the different silicas in Figure 3.5 are compared with the $\mathrm{C}_{2}+$ oxygenate STYs for the RhMn and RhMnIr catalysts on the same supports, there is no regular trend between the Na content and the STY. 
Magnesium was a significant contaminant in the Engelhard Mod D and Norpro SS61137 silica supports with M:Rh ratios of 0.05:1 and 0.02:1, respectively. An earlier test with Mg added to the baseline RhMn/Davisil silica catalyst in a second impregnation at a Mg:Rh ratio of 0.1:1 was significantly less active than the unpromoted catalyst but more active than the Na-promoted catalyst, achieving a $\mathrm{C}_{2}+$ oxygenate STY of $230 \mathrm{~g} / \mathrm{kg}_{\mathrm{cat}} / \mathrm{hr}$ at $275^{\circ} \mathrm{C}$. In a more recent test discussed in Section 3.3.1, a baseline $\mathrm{RhMnIr} / \mathrm{SiO}_{2}$ co-impregnated with $\mathrm{Mg}$ at a $\mathrm{Mg}: \mathrm{Rh}$ atomic ratio of 0.03:1 was both very active and selective to $\mathrm{C}_{2}+$ oxygenates ( $1100 \mathrm{~g} / \mathrm{kg}_{\text {cat }} / \mathrm{hr}_{2}+$ oxygenate STY and $62 \%$ selectivity to $\mathrm{C}_{2}+$ oxygenates). This suggests that the presence of even relatively small concentrations of $\mathrm{Mg}$ could exhibit either detrimental or beneficial effects on the RhMn catalyst depending on whether Ir also is added to the catalyst.

Calcium is found in atomic ratios comparable to the lower end of $\mathrm{Na}$ on some of the silica supports with Ca:Rh atomic ratios of 0.02 on Merck Grade 60 and 0.035 on Merck Grade 7734. It might be expected to have detrimental and/or beneficial effects as a promoter, considering the effects of $\mathrm{Mg}$.

The other contaminants, Fe, titanium, zirconium, and silicon, are present in lower concentrations than the aforementioned contaminants. While they likely do not have significant effects on catalyst performance, they cannot be entirely discounted.

Based on the test results, and support characterizations, very little can be concluded at this time regarding the effect of silica support properties on catalyst performance for either the $\mathrm{RhMn} / \mathrm{SiO}_{2} \mathrm{catalyst}$ of the $\mathrm{RhMnIr} / \mathrm{SiO}_{2}$ catalyst. There do not appear to be any clear trends in catalyst performance with respect to individual properties, because there are exceptions for each. For example the Davisil 645 silica and the two Norpro silicas have similar surface areas and nominal pore sizes, but the RhMn on the Davisil silica is significantly more active in terms of $\mathrm{C}_{2}+$ oxygenate STYs, than those made with the Norpro silicas.

The role of silica acidity as measured by $\mathrm{NH}_{3}$ desorption does not appear to provide any trend with respect to catalyst performance. Finally, it is possible that some of the contaminants in the silicas affect catalyst performance, but again there does not appear to be any clear trend with any one contaminant. Contaminants also can be expected to influence the catalyst selectivities to the various products, but again, there do not appear to be any clear trends at this time. Further examination of the silica support effects, through additional testing, and perhaps testing of acid treated silicas may provide additional insight. However, based on what is known at this time, the Davisil appears to have the best overall combination of high STYs and selectivities to $\mathrm{C}_{2}+$ oxygenates with and without Ir promotion of the $\mathrm{RhMn} / \mathrm{SiO} 2$ catalyst. None of the other supports achieved as high STYs and only the two Merck silicas achieved significantly higher converted carbon selectivities to the $\mathrm{C}_{2}+$ oxygenates, which would warrant further consideration at this time.

\subsubsection{Carbon Supports}

Experiments were conducted on the RhMnIr/carbon catalysts system using four alternative carbon supports for comparison to earlier tests performed using the Hyperion CS-02C-063 multi-walled carbon nanotube support. The following carbon supports were tested:

- Hyperion CS-02D-063

- Hyperion CS-02E-063 
- Hyperion CS-07C-063

- Timcal Timrex 300.

The Timcal Timrex 300 and Hyperion CS-07C-063 had been tested previously without Ir impregnation. The Hyperion CS-02D-063 and CS-02E-063 carbon supports are variations of the Hyperion CS-02C-063 multi-walled carbon nanotube support. All catalysts contained $11.7 \%$ Rh, 3.6\% Mn, and 2.2\% Ir. All three metals were co-impregnated on the supports. Duplicate tests were performed with catalyst prepared using different batches of the Hyperion-CS-02C-063 support.

Figures 3.6 and 3.7 compare the performance of these RhMnIr catalysts on the various supports at $275^{\circ} \mathrm{C}$. It appears that there are relatively modest differences in the performance of the three variations of the Hyperion CS-02C-063, CS-02D-063, and CS-02E-063 supports. The two catalysts prepared with different lots of the CS-02C-063 support had $\mathrm{C}_{2}+$ oxygenate STYs (688 and $582 \mathrm{~g} / \mathrm{kg}_{\text {cat }} / \mathrm{hr}$ ) that were within $8 \%$ of one another, while their converted carbon selectivities to $\mathrm{C}_{2}+$ oxygenates $(52.6 \%$ and $48.2 \%$ ) were within $9 \%$ of one another. The CS-02D-063 and CS-02E-063 variations had $\mathrm{C}_{2}+$ oxygenate STYs (750 and $770 \mathrm{~g} / \mathrm{kg}_{\text {cat }} / \mathrm{hr}$ ) that were $18 \%$ and $21 \%$ higher, respectively, than the average STY for the two catalysts prepared on the CS-02C-063 support. Similarly, selectivities to $\mathrm{C}_{2}+$ oxygenates (53.4\% and $51.4 \%$ ) were $6 \%$ and $2 \%$ greater than the average selectivity for the CS-02C-063-supported catalyst. The Hyperion CS-07C-063-supported catalyst was much more active than the other three Hyperion carbonsupported catalysts with a $\mathrm{C}_{2}+$ oxygenate STY $\left(1100 \mathrm{~g} / \mathrm{kg}_{\text {cat }} / \mathrm{hr}\right)$ that was about $70 \%$ greater than the average STY for the CS-02C-063-supported catalyst, while the selectivity (51.2\%) was nearly the same ( 2\% greater than average for the CS-02C-063-supported catalysts). The Timcal Timrex 300 graphitic carbon-supported catalyst was the most active with a $\mathrm{C}_{2}+$ oxygenate STY $\left(1250 \mathrm{~g} / \mathrm{kg}_{\text {cat }} / \mathrm{hr}\right)$ that was $98 \%$ greater than the average STY for the Hyperion CS-02C-063-supported catalyst. Its selectivity to $\mathrm{C}_{2}+$ oxygenates (50.3\%) was the same as the average selectivity of the CS-02C-063-supported catalyst.

Based on these results, all five alternative carbon supports have comparable selectivities to $\mathrm{C}_{2}+$ oxygenates, and very good STYs, with both the Hyperion CS-07C-063 and the Timrex Timcal 300 having significantly higher STYs. Furthermore, the STYs of the latter two carbon supports have STYs that are significantly higher than those achieved with the Davisil 645 silica, while attaining slightly higher carbon selectivities to $\mathrm{C}_{2}+$ oxygenates (see Figures 3.3 and 3.4), albeit using higher concentrations of metals on the catalysts. 


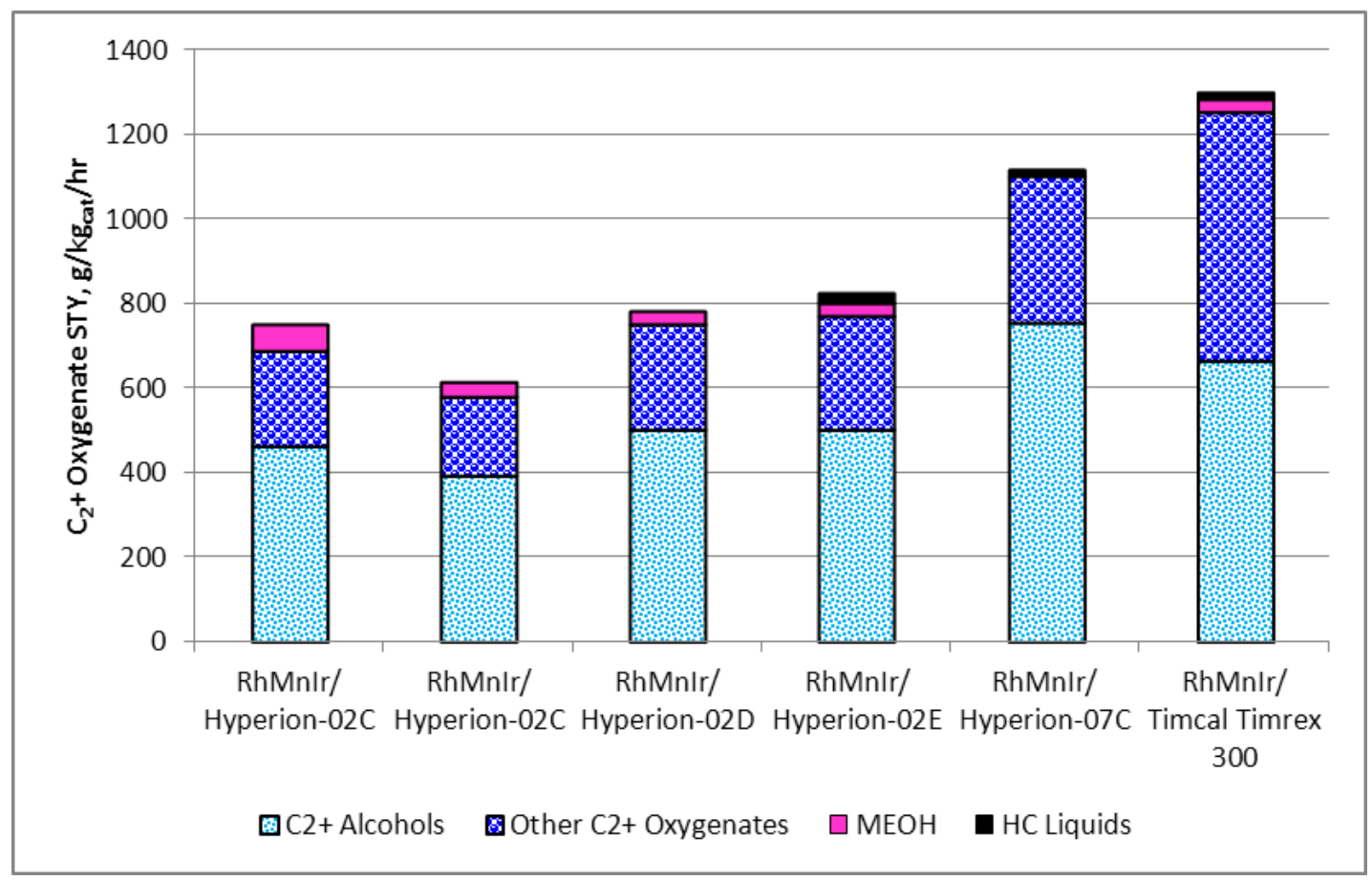

Figure 3.6. Comparison of the Effect of Carbon Support on $\mathrm{C}_{2}+$ oxygenate STYs for RhMnIr/Carbon Catalysts at $275^{\circ} \mathrm{C}$

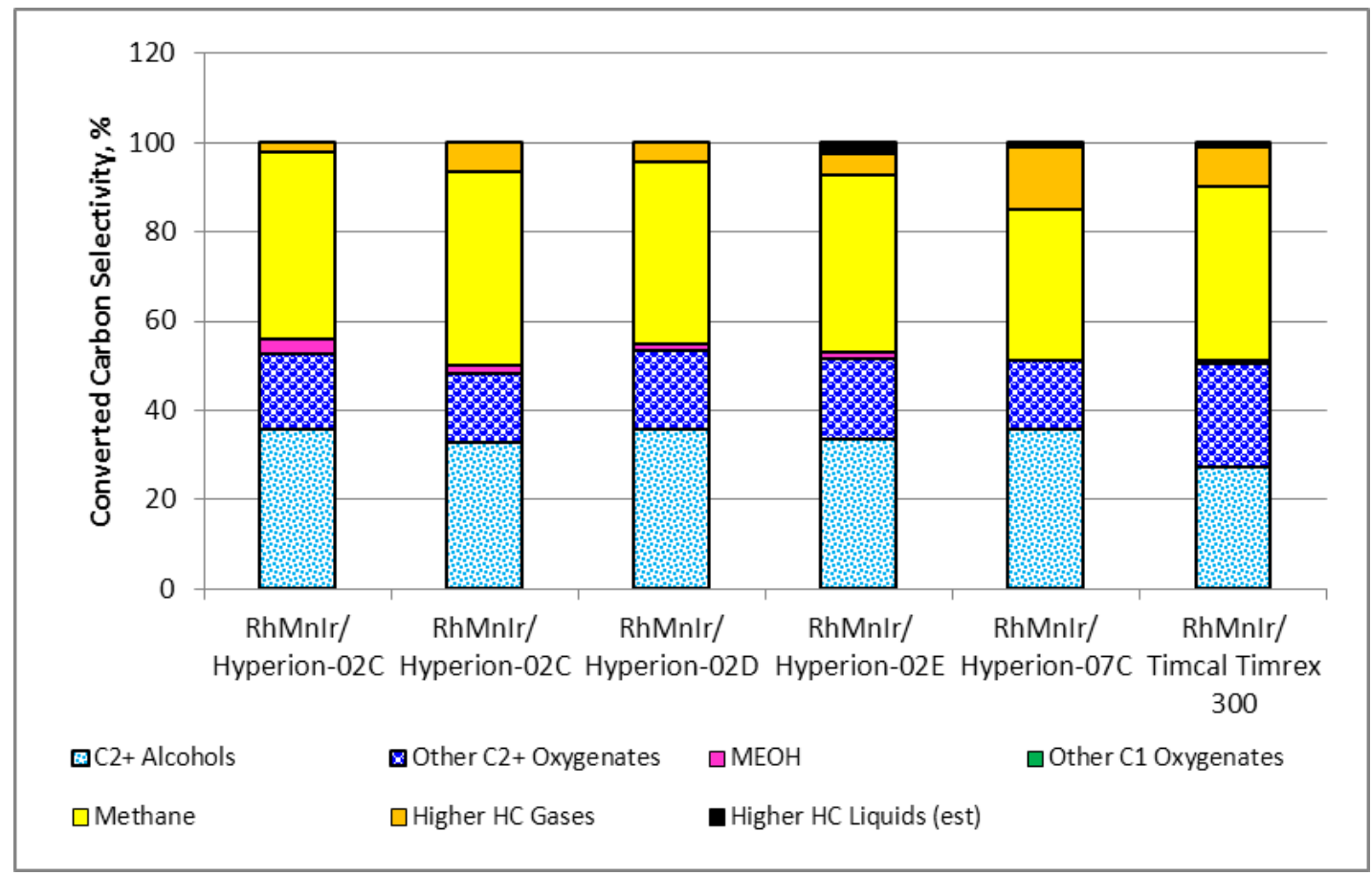

Figure 3.7. Comparison of the Effect of Carbon Support on Converted Carbon Selectivities to $\mathrm{C}_{2}+$ Oxygenates for RhMnIr/Carbon Catalysts at $275^{\circ} \mathrm{C}$ 


\subsection{Optimization of RhMnIr/SiO2 Catalysts}

Optimization of the Davisil silica-supported RhMnIr catalyst began in FY 2010, with optimization based around a baseline catalyst composition containing $5.56 \mathrm{Rh}, 1.69 \% \mathrm{Mn}$ and, if present, 1.03\% Ir. These concentrations produce a Rh:Mn:Ir atomic ratio of 1:0.57:0.1. Optimization of the RhMn catalysts examined the total metals concentration at the baseline atomic ratio for $\mathrm{Rh}$ and $\mathrm{Mn}$, and the $\mathrm{Mn}$ concentration on catalysts containing the baseline concentration of Rh. Optimization of the RhMnIr catalyst examined the Ir concentration using baseline concentrations of $\mathrm{Rh}$ and $\mathrm{Mn}$ in the catalysts. Not investigated were the effect of total metals for the RhMnIr catalyst and catalysts with a baseline concentration of Rh and different concentrations of both Mn and Ir.

During FY 2011, research was continued to further optimize RhMnIr catalysts on Davisil 645 silica supports, with both co-impregnated and double-impregnated catalysts. Research also was expanded to include the Merck Grade 7734 silica support because of the high selectivities to $\mathrm{C}_{2}+$ oxygenates that were achieved when it was used.

In most of the tests conducted during FY 2011, double-impregnated catalysts were examined, in part to see if higher STYs could be produced that were comparable to the better performing Merck Grade 60 silica-supported, double-impregnated RhMnIr catalysts. However, as has been previously discussed, the double-impregnation technique produced considerable data scatter in in the catalyst performance metrics. The results discussed below are presented at this time to document progress on this activity, recognizing that further testing with single-impregnated catalysts would be needed to fully explore the parameters examined this year.

\subsubsection{Davisil 645 Silica-Supported Catalysts}

Figures 3.8 and 3.9 compare the $\mathrm{C}_{2}+$ oxygenate STYs and converted carbon selectivities to $\mathrm{C}_{2}+$ oxygenates at $1200 \mathrm{psig}, 275^{\circ} \mathrm{C}$, and $7500 \mathrm{~L} / \mathrm{Lcat} / \mathrm{hr}$ GHSVs in tests to further optimize the Davisil silicasupported RhMnIr catalysts. The first four catalysts in the figures compare catalysts that were prepared using a single co-impregnation of all three metals but in different concentrations relative to the baseline concentrations of $5.56 \% \mathrm{Rh}, 1.69 \% \mathrm{Mn}$, and $1.03 \%$ Ir. In Figure 3.8, it appears that increasing only the Ir concentration, or increasing both the $\mathrm{Mn}$ and Ir concentrations simultaneously, causes a reduction in the $\mathrm{C}_{2}+$ oxygenate STYs and a significant increase in the production of hydrocarbon liquids. Figure 3.9 shows that increasing the Ir concentration or both the $\mathrm{Mn}$ and Ir concentrations also reduced the converted carbon selectivity to $\mathrm{C}_{2}+$ oxygenates, mainly at the expense of increased selectivity to hydrocarbon liquids.

As previously discussed, catalysts prepared using two impregnations (double impregnations) with Rh and $\mathrm{Mn}$ added in the first impregnation and Ir added in the second, produced considerable scatter in the catalyst performance data. Thus, little can be said about the performance of the second set of four catalysts in which Rh and Mn were co-impregnated at their baseline concentrations and Ir was added in a second impregnation at concentrations of $1 \mathrm{X}, 1.5 \mathrm{X}$ and $2 \mathrm{X}$ of its baseline concentration. The main observation with these catalysts was that none of them performed as well as the $1 \mathrm{X}$ baseline RhMnIr catalyst prepared using a single impregnation of all three metals. The last catalyst shown in the Figures 3.8 and 3.9 also was prepared using two impregnations, but the baseline atomic ratio was maintained while the total metals were increased to $1.5 \mathrm{X}$ their baseline concentrations. It is noteworthy that the $\mathrm{C}_{2}+$ 


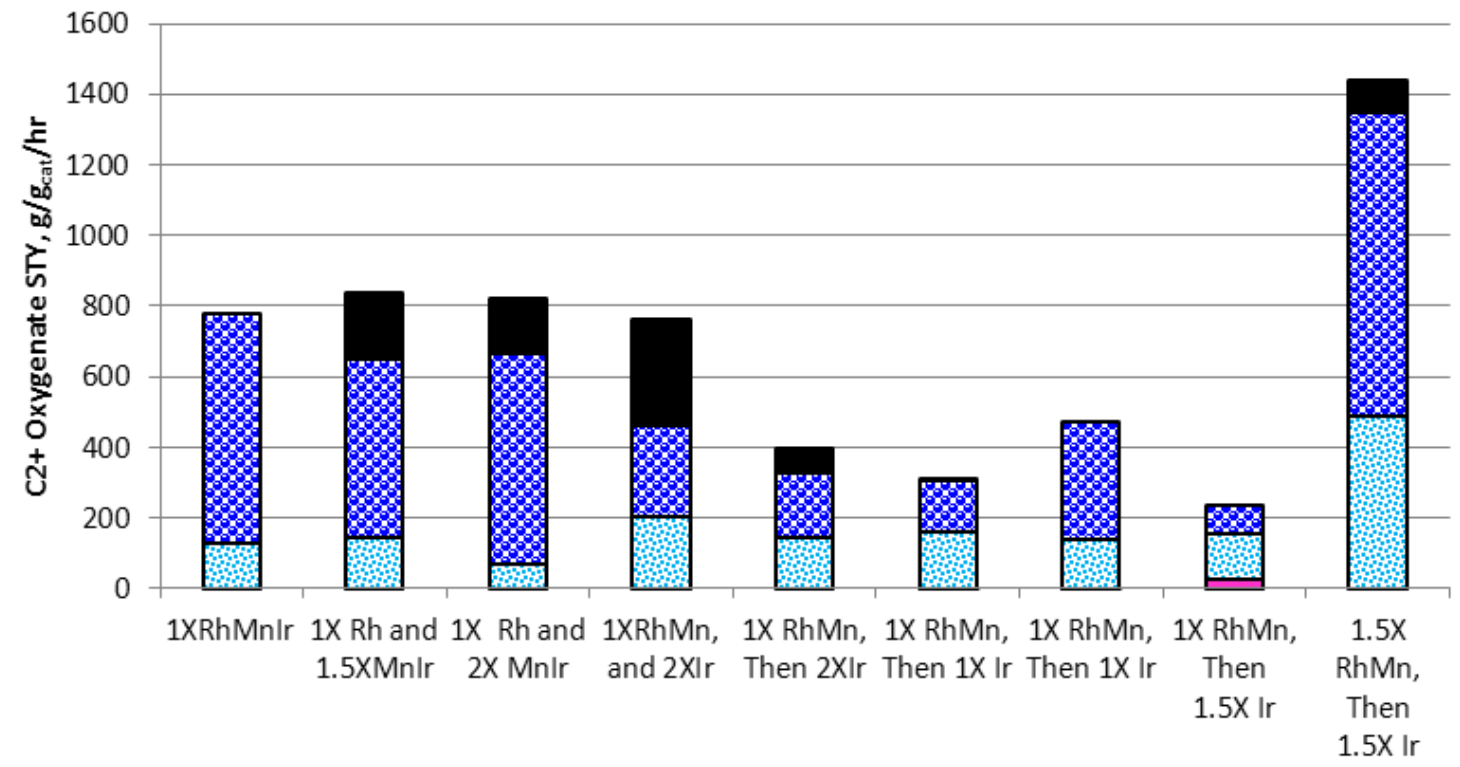

$\square \mathrm{MEOH}$ 固C2+Alcohols OHC Liquids

Figure 3.8. Effect of Ir and Mn+ Ir Concentrations on $\mathrm{C}_{2}+$ Oxygenate STYs on Davisil 645 SilicaSupported Catalysts at $275^{\circ} \mathrm{C}$

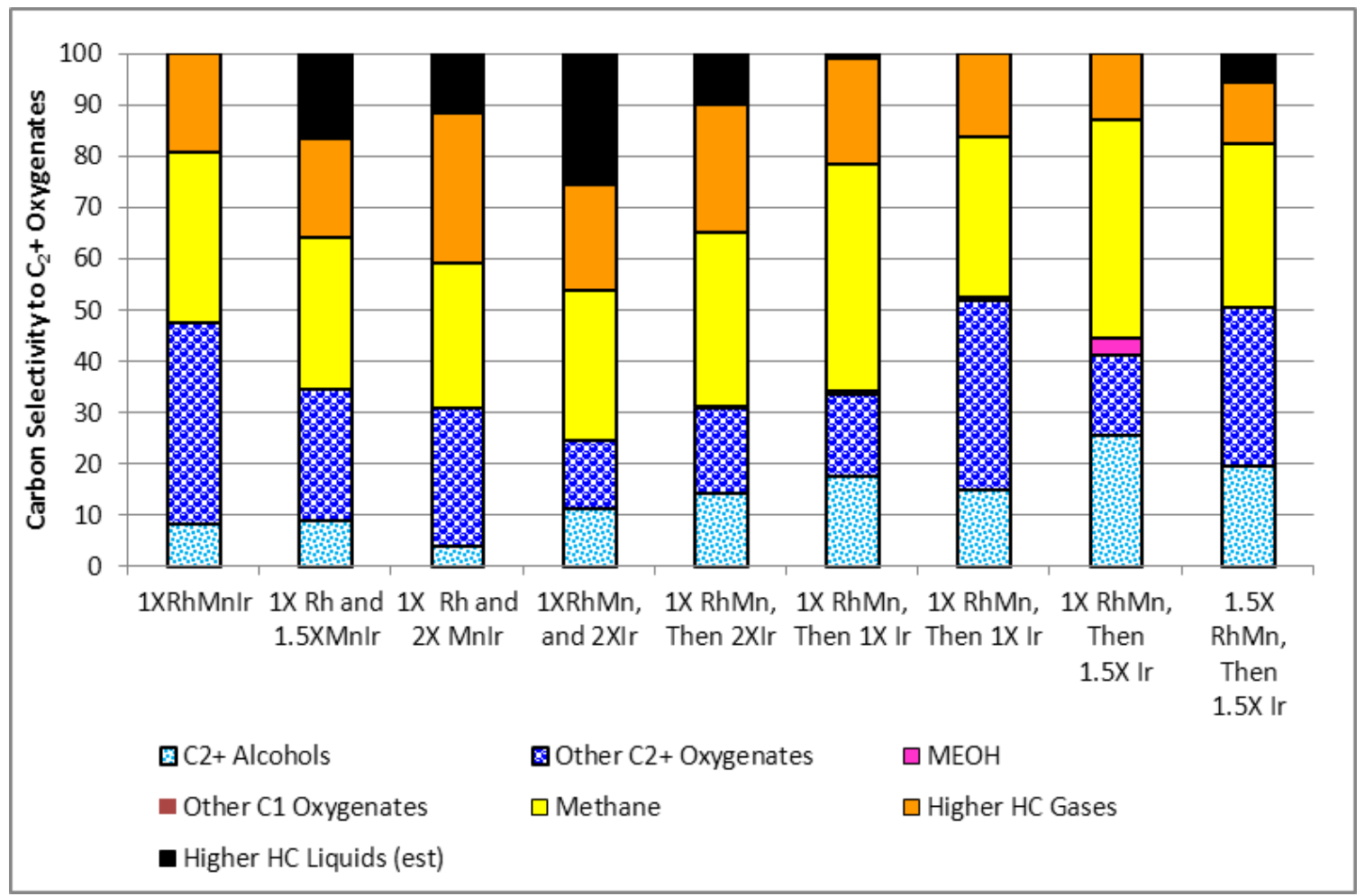

Figure 3.9. Effect of Ir and $\mathrm{Mn}+\mathrm{Ir}$ Concentrations on Converted Carbon Selectivities to $\mathrm{C}_{2}+$ Oxygenate STYs on Davisil 645 Silica-Supported Catalysts at $275^{\circ} \mathrm{C}$ 
oxygenates STY for this catalyst was 75\% greater than the co-impregnated catalyst that had the baseline concentrations of all three metals. It was also nearly three times as high as the STY for the better of the two catalysts prepared at the baseline concentrations but with Ir added in a second impregnation. At the same time, the converted carbon selectivity to $\mathrm{C}_{2}+$ oxygenates was essentially the same as that achieved at the same temperature with the co-impregnated catalyst and the better of the two double impregnated catalysts with the baseline concentrations of all three metals. This behavior is very different from the results obtained in earlier research with the RhMn catalysts supported on Davisil (not promoted with Ir). In those tests, increasing the baseline concentrations of Rh and Mn while maintaining the baseline atomic ratios resulted in very active catalysts in terms of carbon conversion even at temperatures as low as $245^{\circ} \mathrm{C}$, but they mostly made hydrocarbons rather than oxygenates even at the lower temperatures.

\subsubsection{Merck Grade 7734 Silica-Supported Catalysts}

Figures 3.10 and 3.11 compare the $\mathrm{C}_{2}+$ oxygenate STYs and converted carbon selectivities to $\mathrm{C}_{2}+$ oxygenates at $1200 \mathrm{psig}, 275^{\circ} \mathrm{C}$, and $7500 \mathrm{~L} / \mathrm{L}_{\mathrm{cat}} / \mathrm{hr} \mathrm{GHSV}$ in tests to further examine the potential of the Merck Grade 7734 silica-supported RhMnIr catalysts. All of the RhMnIr catalysts were prepared by adding $\mathrm{Rh}$ and $\mathrm{Mn}$ in one impregnation and $\mathrm{Ir}$ in a second impregnation.

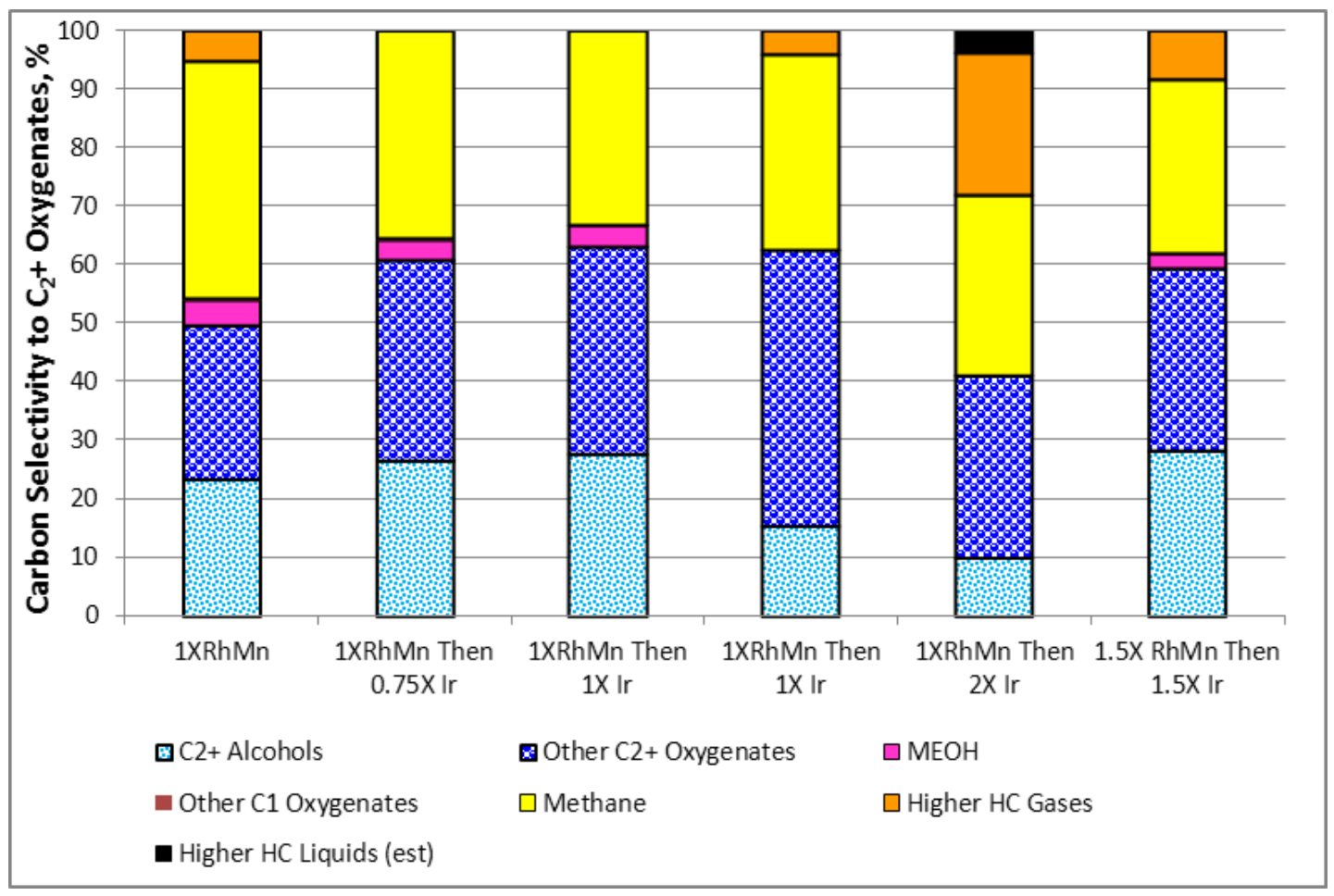

Figure 3.10. Effect of Ir and Mn+ Ir Concentrations on $\mathrm{C}_{2}+$ Oxygenate STYs on Merck Grade 7734 Silica-Supported Catalysts at $275^{\circ} \mathrm{C}$ 


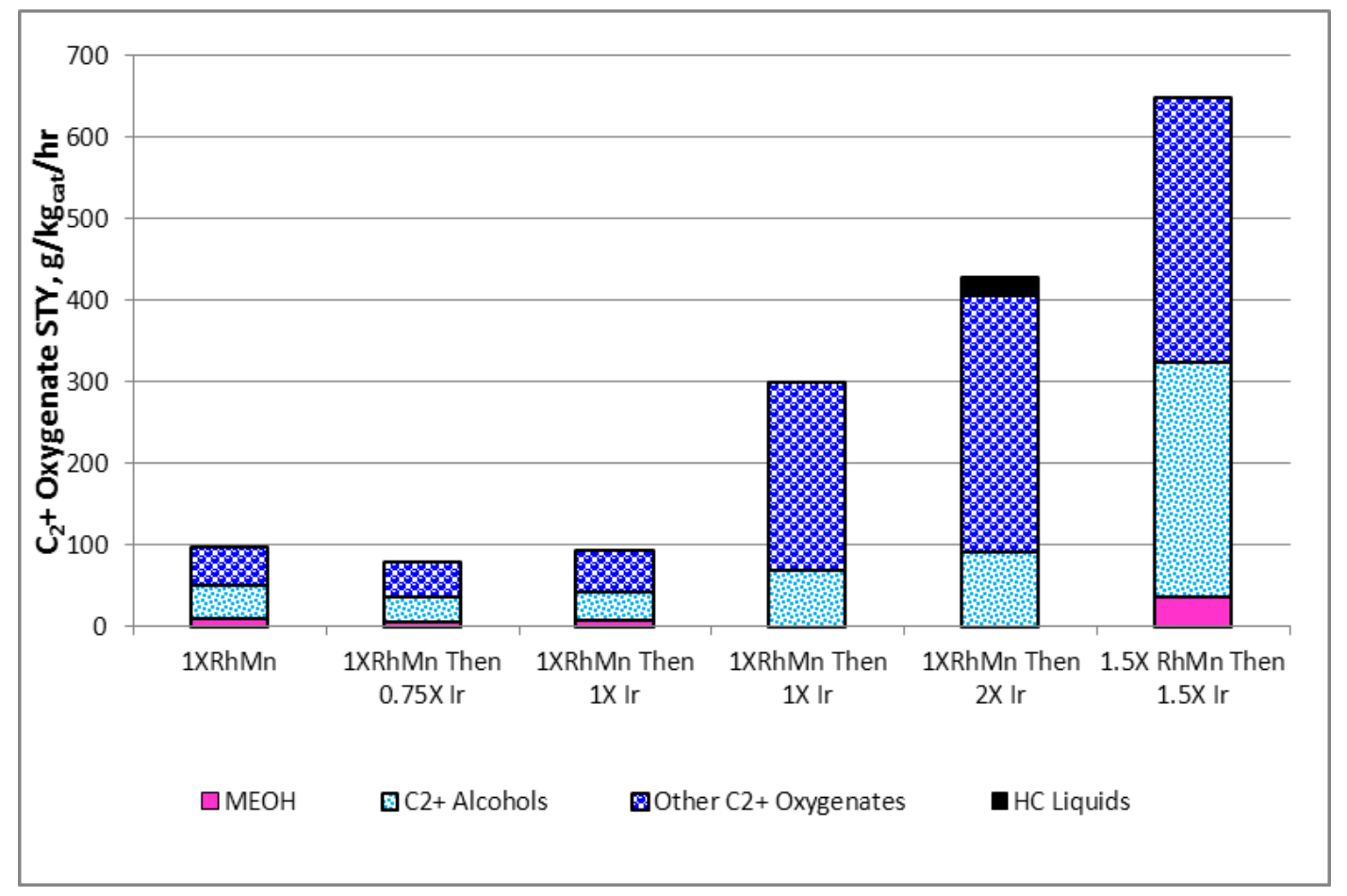

Figure 3.11. Effect of Ir and $\mathrm{Mn}+\mathrm{Ir}$ Concentrations on Converted Carbon Selectivities to $\mathrm{C}_{2}+$ Oxygenate STYs on Merck Grade 7734 Silica-Supported Catalysts at $275^{\circ} \mathrm{C}$

As expected, there was considerable scatter in the data for duplicate tests using catalysts prepared using the same metal concentrations, but in different batches. However, it does appear that increasing the concentrations of all three metals above the baseline level by $1.5 \mathrm{X}$ while maintaining the baseline atomic ratios resulted in $\mathrm{C}_{2}+$ oxygenate STYs that were more than double that of the best performing catalyst with the $1 \mathrm{X}$ baseline metals concentrations prepared in the same manner (i.e., with double impregnations). Furthermore, the converted carbon selectivity to $\mathrm{C}_{2}+$ oxygenates remained near $60 \%$ for the catalyst prepared with 1.5X baseline concentrations (see Figure 3.11). This latter observation is noteworthy because it suggests that co-impregnated catalysts with the same higher catalytic metals atomic ratio, but higher total metal concentrations, may achieve relatively high STYs while maintaining the high selectivities observed for the Merck Grade 7734 silica-supported catalysts.

\subsection{Evaluation of Promoters for the RhMnIr Catalysts}

During FY2011, research was initiated to evaluate the potential for further improving catalyst performance by adding one or two additional metals to the catalysts containing Rh, Mn, and Ir. This research was conducted using the Davisil 645 silica and Hyperion CS-02C-063 carbon supports, which have been extensively evaluated in the past. The fourth components selected for screening were based on those which displayed favorable performance features when used in place of Ir in three component catalysts containing $\mathrm{Rh}$ and $\mathrm{Mn}$. In addition, to determine whether their inclusion together would promote greater selectivity to alcohols, metal combinations were selected based on their documented use in methanol-synthesis catalysts. The test results achieved during FY 2011 are discussed in the following subsections. 


\subsubsection{Silica-Supported Catalysts}

Several tests were performed to evaluate the effects of adding a fourth or a combination of a fourth and fifth metal to the RhMnIr/SiO${ }_{2}$ catalyst. Eight tests were conducted with the Davisil silica, all using the baseline concentrations of 5.56\% Rh, 1.69\% Mn, and 1.03\% Ir and selected additional metal and metal combinations. All metals were co-impregnated on the silica support along with the Rh, Mn, and Ir. The following promoters were investigated:

- $0.005 \%$ Ga $(\mathrm{Rh}: \mathrm{Ga}=750: 1)$

- $0.04 \%$ Mg (Rh:Mg = 33:1)

- $0.09 \%$ V (Rh:V = 33:1)

- $0.25 \% \mathrm{La}(\mathrm{Rh}: \mathrm{La}=33: 1)$

- $0.02 \%$ B (Rh:B = 33:1)

- $0.26 \%$ Pt (Rh:Pt = 40:1)

- $0.059 \% \mathrm{Zn}+0.057 \% \mathrm{Cu}(\mathrm{Rh}: \mathrm{Zn}: \mathrm{Cu}=60: 1: 1)$

- $0.06 \% \mathrm{Zn}+0.10 \%$ Pd (Rh:Zn:Pd = 60:1:1).

Most of the promoters were added at concentrations that were $30 \%$ of the concentrations used when the same promoters were added in place of Ir as a third metal to $\mathrm{RhMn} / \mathrm{SiO}_{2}$ catalysts in earlier research. Platinum was added at $25 \%$ of the concentration used in earlier research because it was known to produce very active catalysts when used in place of Ir. The combinations $\mathrm{Zn}+\mathrm{Cu}$ and $\mathrm{Zn}+\mathrm{Pd}$ were added in equal atomic concentrations to each other and with a total concentration that was approximately one-third of the concentrations used for the metals when added as a third promoter. These combinations were selected because they are known to produce high yields of methanol. Gallium was added at a Rh:Ga atomic ratio of $750: 1$, because in earlier research when it was added as a third metal to the $\mathrm{RhMn} / \mathrm{SiO} 2$ catalyst, it had favorable catalytic effects at very low concentrations. Tests were conducted at 1200 psig, $7500 / \mathrm{hr}$ GHSV and sequentially at $240^{\circ} \mathrm{C}, 256^{\circ} \mathrm{C}$, and $275^{\circ} \mathrm{C}$, with the latter condition used for comparing the catalysts.

Figures 3.12 and 3.13 compare the effects of the different promoters on catalyst performance relative to those for the unpromoted $\mathrm{RhMnIr} / \mathrm{SiO}_{2}$ catalyst at the common test conditions of $1200 \mathrm{psig}, 275^{\circ} \mathrm{C}$, and $1500 \mathrm{~L} / \mathrm{L}_{\text {cat }} / \mathrm{hr}$ GHSV. The addition of Mg, La, V, or Pt to the baseline $\mathrm{RhMnIr} / \mathrm{SiO}_{2}$ catalyst increased the $\mathrm{C}_{2}+$ oxygenate $\mathrm{STY}$ by $38 \%, 30 \%$, 31\%, and $19 \%$, respectively over the average STY achieved by the unpromoted catalyst. These promoters also achieved converted carbon selectivities to $\mathrm{C}_{2}+$ oxygenates that were $38 \%, 15 \%, 12 \%$, and $2 \%$ better, respectively, than the average selectivity achieved by the unpromoted catalyst. While the effects of $\mathrm{Mg}$ addition were the most pronounce in terms of both STY and selectivity, all of these promoters warrant further optimization with respect to their concentration in the catalyst so their performances at optimum concentrations can be compared.

Addition of $\mathrm{Zn}+\mathrm{Cu}$ or $\mathrm{Zn}+\mathrm{Pd}$ to the catalyst produced selectivities that were comparable to the $\mathrm{Mg}$ promoted catalysts, (35\% and 30\% higher than the unpromoted catalyst, respectively), but both were significantly less active than the unpromoted catalyst (78\% and $60 \%$ of the unpromoted catalyst STY). Both catalysts also achieved greater selectivities to $\mathrm{C}_{2}+$ alcohols, relative to the baseline $\mathrm{RhMnIr} / \mathrm{SiO}_{2}$ 


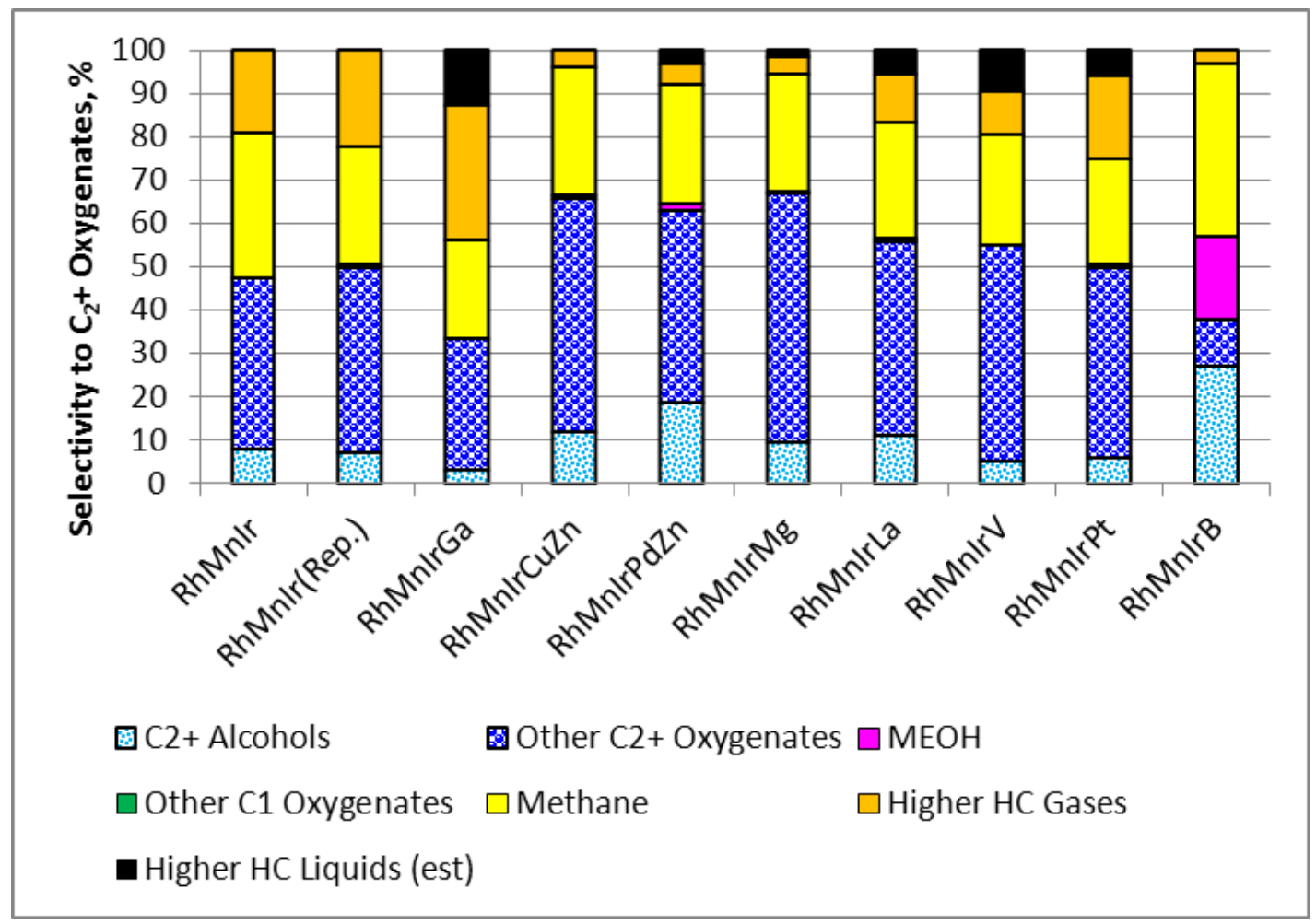

Figure 3.12. Effects of Different Promoters on STYs at $275^{\circ} \mathrm{C}$

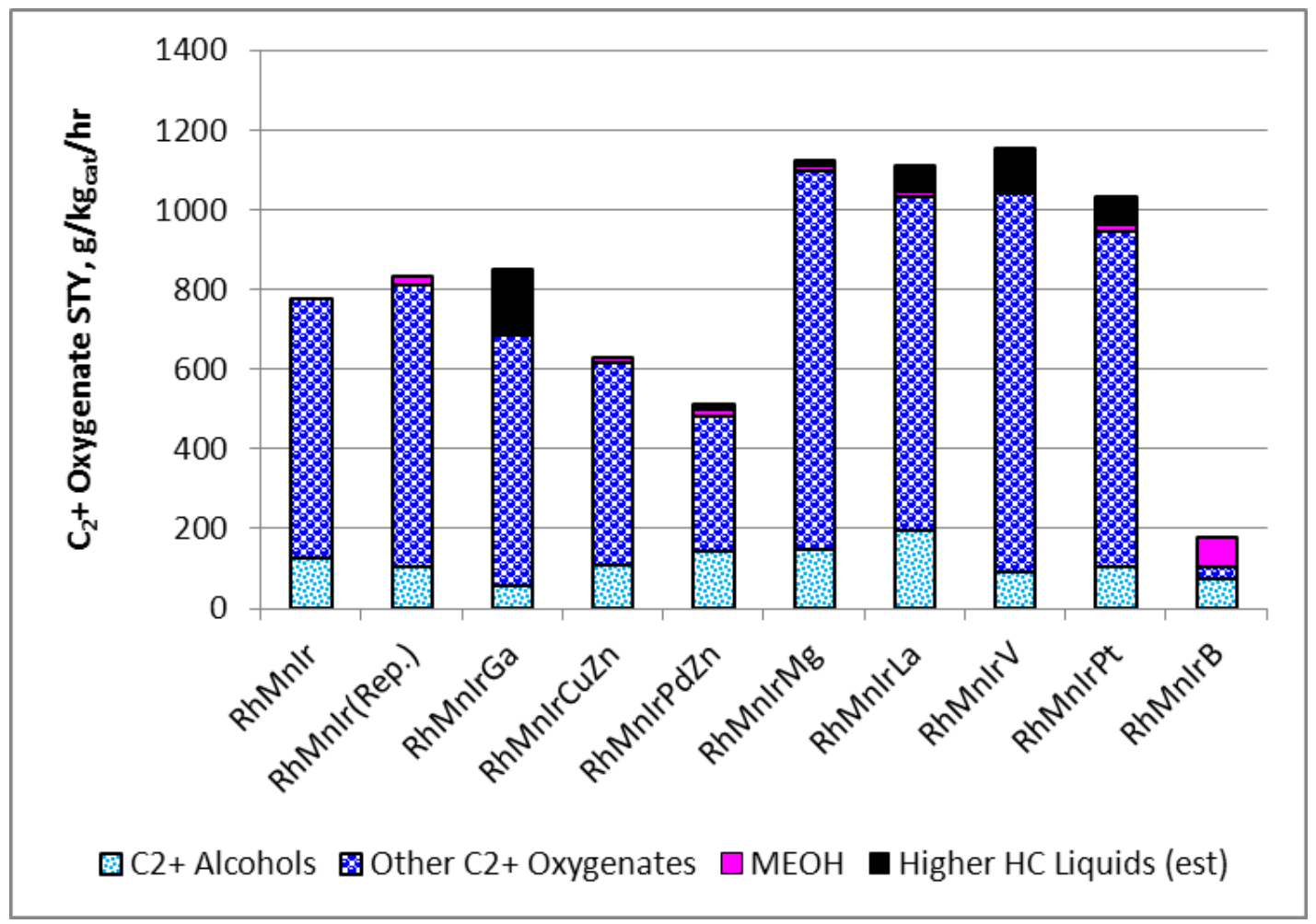

Figure 3.13. Effects of Different Promoters on Converted Carbon Selectivities at $275^{\circ} \mathrm{C}$ 
catalyst, but not to any degree of significance as might be beneficial to downstream processing to hydrogenate the mixed oxygenate products. The overall performance of the $\mathrm{Cu}-\mathrm{Zn}$ promoted catalyst at all temperatures tested appeared to be superior to the Pd-Zn promoted catalyst. Further optimization of the Cu-Zn promoted catalyst may also be warranted to determine if its STY can be improved without sacrificing selectivity.

The B-promoted catalyst was not very active, and its selectivity to $\mathrm{C}_{2}+$ oxygenates also was much lower than the unpromoted catalyst. It is noteworthy, however, that the overall selectivity to all oxygenates (including methanol) was higher than the unpromoted catalyst. This type of performance would justify testing at lower concentrations to determine if reduced concentrations could improve the catalyst activity.

The Ga-promoted catalyst had an STY that was nearly as high as the unpromoted catalyst but the selectivity to $\mathrm{C}_{2}+$ oxygenates was much lower. Further evaluation of this promoter is not justified at this time.

\subsubsection{Carbon-Supported Catalysts}

Several tests were performed using the Hyperion CS-02C-063 multi-walled carbon nanotube support to evaluate the effects of adding a fourth or a combination of a fourth and fifth metal to the

$\mathrm{RhMnIr/carbon} \mathrm{catalyst.} \mathrm{Catalysts} \mathrm{were} \mathrm{prepared} \mathrm{using} \mathrm{the} \mathrm{baseline} \mathrm{concentrations} \mathrm{of} 11.7 \% \mathrm{Rh}, 3.57 \%$ Mn, 2.17\% Ir, and selected additional metal and metal combinations. All metals were co-impregnated on the carbon support along with the Rh, Mn, and Ir. The following promoters were investigated:

- $0.07 \%$ Fe (Rh:Fe = 90:1)

- $0.20 \% \mathrm{Fe}(\mathrm{Rh}: \mathrm{Fe}=30: 1)$

- $0.24 \% \mathrm{Zn}(\mathrm{Rh}: \mathrm{Zn}=30: 1)$

- $0.09 \%$ Mg (Rh:Mg = 30:1)

- $0.53 \% \mathrm{La}(\mathrm{Rh}: \mathrm{La}=30: 1)$

- $0.19 \%$ V (Rh:V = 30:1)

- $0.04 \%$ B (Rh:B = 30:1)

- $0.55 \% \mathrm{Pt}(\mathrm{Rh}: \mathrm{Pt}=30: 1)$

- $0.01 \%$ Ga (Rh:Ga = 800:1)

- $0.10 \%$ Fe, 0.12\% Zn (Rh:Fe:Zn = 60:1:1)

- $0.12 \% \mathrm{Cu}, 0.12 \% \mathrm{Zn}(\mathrm{Rh}: \mathrm{Cu}: \mathrm{Zn}=60: 1: 1)$

- $0.20 \%$ Pd, 0.12\% Zn (Rh:Pd:Zn = 60:1:1).

Most of the promoters (Fe, Mg, B, La, V, and Pt) were selected because they had favorable effects on catalyst performance when added in place of Ir as a third promoter on the RhMn/carbon catalysts. In this test series, they were added at approximately one-third of the concentration used when added in place of Ir (a second concentration of Fe at a 90:1 Rh:Fe atomic ratio was also examined). Ga was selected because earlier tests suggested that it had a favorable effect when added at very low concentrations 
(Rh:Ga atomic ratio of 800:1) as a third component in place of Ir. The combinations $\mathrm{Zn}+\mathrm{Fe}, \mathrm{Zn}+\mathrm{Cu}$ and $\mathrm{Zn}+\mathrm{Pd}$ were added in equal atomic concentrations to each other and with a total concentration that was one-third of the concentrations used for the metals when added individually as a third promoter. Copper and Pd were each used in combination with Zn to introduce combinations known to promote methanol synthesis, while Fe was used in combination with $\mathrm{Zn}$ for comparison to the other two combinations.

Figures 3.14 and 3.15 compare the effects of the different promoters on catalyst performance at the common test conditions of $1200 \mathrm{psig}, 275^{\circ} \mathrm{C}$, and $1500 \mathrm{~L} / \mathrm{L}_{\mathrm{cat}} / \mathrm{hr} \mathrm{GHSV}$. Also shown for comparison in the figures are the results from unpromoted RhMnIr/carbon catalysts made from three different batches. It can be seen from the figures that there was significant variation in the performances of the three different batches of the unpromoted catalyst shown with the red dashed lines. The $\mathrm{C}_{2}+$ oxygenate STYs ranged from about 490 to $690 \mathrm{~g} / \mathrm{kg}_{\text {cat }} / \mathrm{hr}$, which is about $\pm 17 \%$ about the midpoint value of $590 \mathrm{~g} / \mathrm{kg}_{\text {cat }} / \mathrm{hr}$. Similarly, the converted carbon selectivity to $\mathrm{C}_{2}+$ oxygenates ranged from about $48.1 \%$ to $52.6 \%$ with a midpoint value of $52.4 \%$, which is about $\pm 4 \%$ about the midpoint value.

All of the promoters and promoter combinations achieved $\mathrm{C}_{2}+$ oxygenates STYs that were greater than the highest value for the unpromoted catalyst, although the $\mathrm{Zn}$ and La promoted catalysts were only marginally so. The most noteworthy catalysts in terms of STYs were the Pt and Ga promoted catalysts, which had STYs of 1700 and $1300 \mathrm{~g} / \mathrm{kg}_{\text {cat }} / \mathrm{hr}$, respectively, which were $2.9 \mathrm{X}$ and 2.2X higher than the midpoint STY value for the unpromoted catalysts. Both promoted catalysts had converted carbon selectivities that were slightly lower than the lowest value reported for the unpromoted catalyst. Further examination of the tests with these promoters suggest that higher GHSVs and/or lower operating temperatures could be employed to significantly improve their selectivity, while still attaining superior STYs.

The B-promoted catalyst also was noteworthy because it attained the best combination high $\mathrm{C}_{2}+$ oxygenate STY and selectivity (>1000 g/ $\mathrm{kg}_{\text {cat }} / \mathrm{hr}$ and 56\%, respectively), which were $75 \%$ and $11 \%$ greater than the midpoint values for the unpromoted catalysts, respectively. The B-promoted catalyst also displayed favorable characteristics at other operating conditions (i.e., temperature and GHSVs).

The individual promoters, Mg and V, and the combined promoters using $\mathrm{Zn}$ and either $\mathrm{Fe}, \mathrm{Cu}$, or $\mathrm{Pd}$ were also of interest because they had STYs ranging from $45 \%$ to $71 \%$ greater than the midpoint STY for the unpromoted catalyst, and had selectivities that ranged from about the same to $10 \%$ greater than the unpromoted catalysts. When considered in conjunction with the performances of the Fe and Zn individually promoted catalysts, further optimization of $\mathrm{Zn}, \mathrm{Fe}, \mathrm{Cu}$, and $\mathrm{Pd}$ individually and $\mathrm{Fe}, \mathrm{Cu}$, and $\mathrm{Pd}$ in combination with $\mathrm{Zn}$ is warranted. 


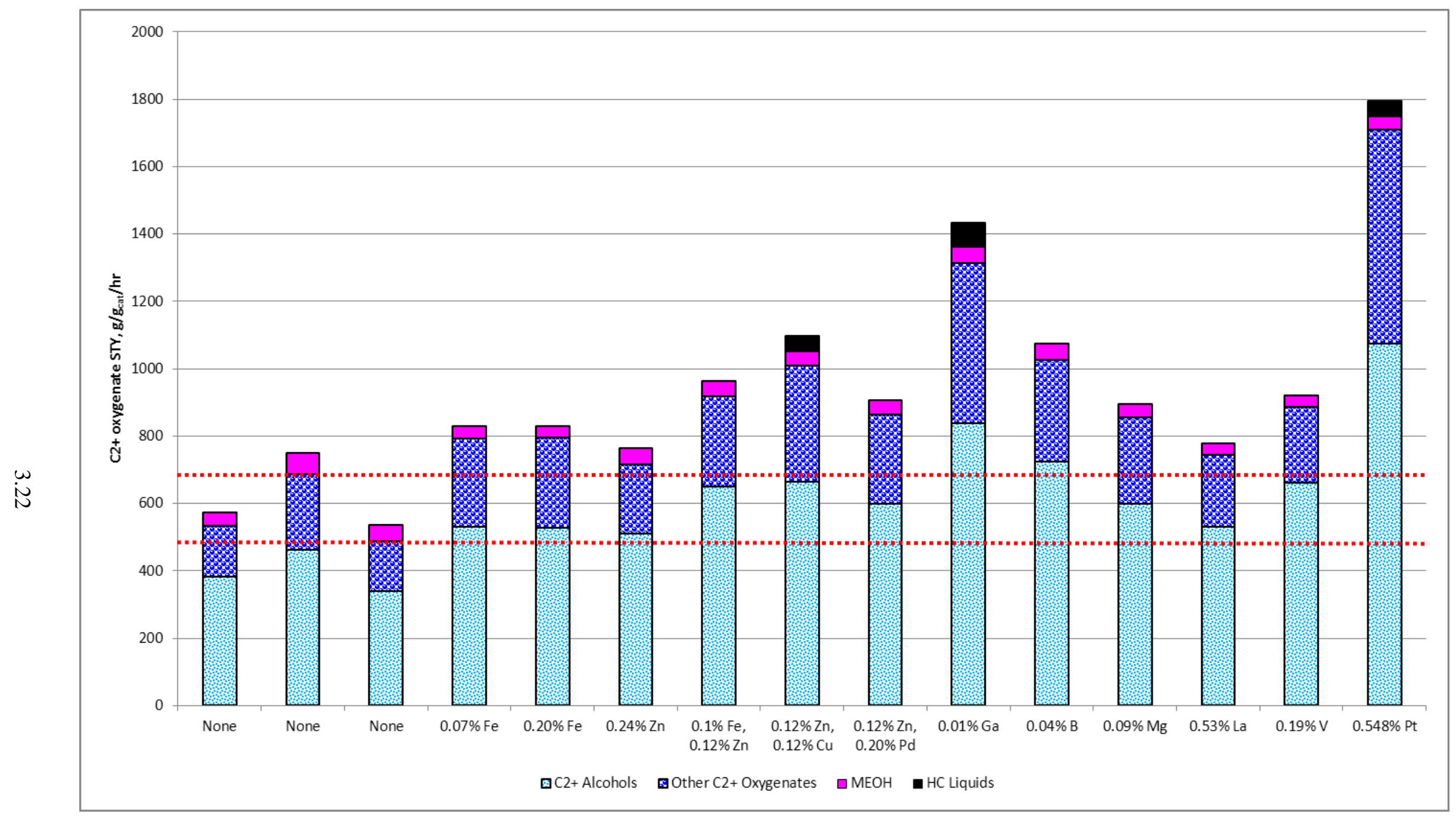

Figure 3.14. Comparison of the Effects of Different Promoters on the STY for the RhMnIr/Carbon Catalyst at $275^{\circ} \mathrm{C}$ (red lines indicate the highest and lowest $\mathrm{C}_{2}+$ oxygenate STYs achieved with the catalysts containing no added promoters) 


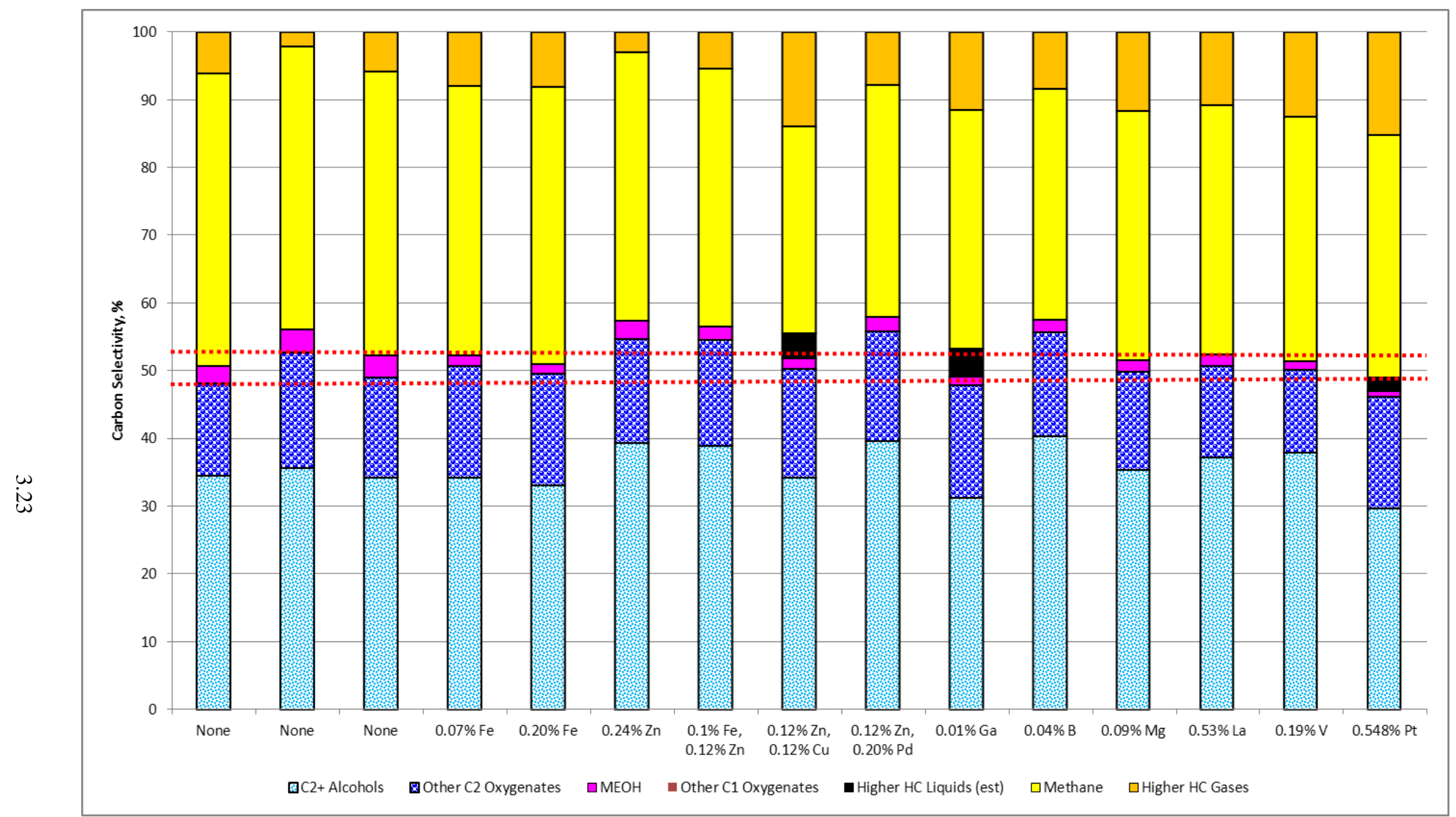

Figure 3.15. Comparison of the Effects of Different Promoters on the Converted Carbon Selectivities for the RhMnIr/Carbon Catalyst at $275^{\circ} \mathrm{C}$ (red lines indicate the highest and lowest converted carbon selectivities to $\mathrm{C}_{2}+$ oxygenates achieved with the catalysts containing no added promoters) 


\subsection{Conclusions}

Tests were continued in FY 2011 to further improve the Ir-promoted RhMn catalysts. This research further examined RhMn catalysts on zeolite supports to compare with similar catalysts prepared on a variety of other alternative supports. In addition, tests were conducted using $\mathrm{Rh}, \mathrm{Mn}$, and Ir on selected silica and carbon supports to identify a preferred support. Tests also were conducted to further optimize the $\mathrm{RhMnIr} / \mathrm{SiO}_{2}$ catalysts using the Davisil 645 and Merck Grade 7734 silica supports to examine compositions not previously evaluated. Finally tests were conducted to evaluate the effects of additional promoters to the RhMnIr catalysts using Davisil 645 silica and Hyperion CS-02C-063 multi-walled carbon nanotubes as supports. Based on the results of these tests a number of general conclusions can be reached.

\subsection{Catalyst Supports}

Zeolite catalyst supports were evaluated using baseline concentrations of Rh and $\mathrm{Mn}$. None of these supports were very good in terms of both $\mathrm{C}_{2}+$ oxygenate STYs and selectivities to $\mathrm{C}_{2}+$ oxygenates compared to selected silica and carbon supports identified in FY 2010.

Tests also were conducted with selected silicas using baseline concentrations of Rh, Mn, and Ir to further evaluate their performance. However, in most cases the Ir was added in a second impregnation (double impregnation). In duplicate tests using different batches of catalysts made with the Davisil 645 and Merck Grade 60 silica supports, it was apparent that there was too much scatter in the STY and selectivity data to draw firm conclusions. However, the combination of high $\mathrm{C}_{2}+$ oxygenate STY and selectivity for one of the double-impregnated catalysts on the Merck Grade 60 silica support warrants further investigation of this support and its replacement, Merck Grade 7734 silica, the latter also having high converted carbon selectivities to $\mathrm{C}_{2}+$ oxygenates, but not as high STYs. It also appears that the converted carbon selectivity to $\mathrm{C}_{2}+$ oxygenates of the double-impregnated RhMnIr/Norpro S61138 silica is nearly as high as that achieved with the better of the two double-impregnated RhMnIr/Davisil silica catalysts, along with one of the higher STYs achieved with any of the silica-supported RhMnIr catalysts. Based on these results, this catalyst could warrant further testing. However, for purposes of further optimization, the Davisil silica support appears to have provided the best overall performance among the silicas tested.

Several characterization analyses were performed this year on the different silicas evaluated in this project to determine whether there were key characteristics that might identify good silica supports. The analyses performed this year included surface area and porosity properties using nitrogen adsorption techniques, $\mathrm{NH}_{3}$ desorption for surface acidity assessment, and ICP analysis for trace elements in the silicas. None of these properties appear to account for the differences in the catalyst performances using the different silica supports, although it is possible that combinations of properties could.

Experiments were conducted on the RhMnIr/carbon catalysts system using four alternative carbon supports for comparison to earlier tests performed using the Hyperion CS-02C-063 multi-walled carbon nanotube support. The Timcal Timrex 300 and Hyperion CS-07C-063 supports had been tested previously without Ir impregnations. The Hyperion CS-02D-63 and CS-02E-063 carbon supports are variations of the Hyperion CS-02C-063 multi-walled carbon nanotube support. All catalysts contained $11.7 \%$ Rh, 3.6\% Mn, and 2.2\% Ir. All three metals were co-impregnated on the supports. Duplicate tests 
were performed with catalysts prepared using different lots of the Hyperion CS-02C-063 support. All five alternative carbon supports had comparable selectivities to $\mathrm{C}_{2}+$ oxygenate, and very good STYs, with both the Hyperion CS-07C-063 and the Timrex Timcal 300 having significantly higher STYs. Furthermore, the STYs of the latter two carbon supports had STYs that were significantly higher than those achieved with the Davisil 645 silica at the same conditions, while attaining slightly higher carbon selectivities to $\mathrm{C}_{2}+$ oxygenates, albeit using higher concentrations of metals on the catalysts.

\subsection{Optimization of Silica-Supported Catalysts}

Catalyst optimization studies using Davisil 645 silica-supported RhMn catalysts continued in FY 2011 to further examine the optimization of RhMnIr catalysts on the Davisil 645 silica support with both co-impregnated and double-impregnated catalysts. The research also was expanded to include the Merck Grade 7734 silica support because of the high selectivities to $\mathrm{C}_{2}+$ oxygenates that were achieved using it. Most of the tests used double-impregnated catalysts, in part to see if higher STYs could be produced that were comparable to the better performing Merck Grade 60 silica-supported catalysts. However, the double-impregnation technique produced considerable scatter in terms of catalyst performance metrics, particularly in terms of the $\mathrm{C}_{2}+$ oxygenate STYs. However, there did appear to be a consistent trend with both supports, whereby increasing the concentrations of all three metals while maintaining the baseline Rh:Mn:Ir atomic ratio of 1:0.57:0.1 significantly improved the STYs while maintaining the converted carbon selectivities to $\mathrm{C}_{2}+$ oxygenates. There were no beneficial trends resulting from increasing only the Ir, or both the Mn and Ir concentrations simultaneously. However, further testing with catalysts prepared with single impregnations of all three metals is warranted to more confidently understand the trends.

\subsection{Evaluation of Promoters for the RhMnIr Catalysts}

Research was initiated in FY 2011 to evaluate the potential for further improvement in catalyst performance by adding one or two additional metals to the catalysts containing Rh, Mn, and Ir. This research was conducted using the Davisil 645 silica and Hyperion CS-02C-063 carbon supports that had been extensively evaluated in the past.

Based on the tests conducted to date using the Davisil 645 silica-supported RhMnIr catalyst, adding $\mathrm{Mg}, \mathrm{La}, \mathrm{V}$, or Pt, at a Rh:M atomic ratio of about 33:1, resulted in $\mathrm{C}_{2}+$ oxygenate STY improvements of $38 \%, 30 \%, 31 \%$, and $19 \%$. At the same time, selectivities to $\mathrm{C}_{2}+$ oxygenates were $38 \%, 15 \%, 12 \%$ and $2 \%$ better, respectively, than the average selectivity achieved by the unpromoted catalyst. While the effects of Mg addition were the most pronounced in terms of both STY and selectivity, all of these promoters warrant further optimization with respect to their concentration in the catalyst so performances at their optimum concentrations can be compared.

Based on the tests conducted to date, using the Hyperion CS-02C-063 carbon-supported RhMnIr catalyst, co-impregnating Fe, Zn, Ga, Mg, La, V, B, or Pt as a fourth component at a Rh:M atomic ratio of about 33:1 resulted in improvements in the $\mathrm{C}_{2}+$ oxygenate STY although only marginally so with the La and V promoters. The most noteworthy catalysts, in terms of STY, were the Pt and Ga promoted catalysts, which had STYs that were 2.9X and 2.2X higher than the unpromoted catalyst. However, both had converted carbon selectivities to $\mathrm{C}_{2}+$ oxygenates that were a little lower than that for unpromoted catalyst. Further examination of the tests with these promoters suggests that higher GHSVs and/or lower 
operating temperatures could be employed to significantly improve their selectivity while still attaining superior STYs. The B-promoted catalyst was also noteworthy because it attained the best combination high $\mathrm{C}_{2}+$ oxygenate STY and selectivities that were $75 \%$ and $11 \%$ greater than the unpromoted catalyst, respectively. The $\mathrm{Mg}$ and $\mathrm{V}$ individual promoters and the combination promoters using $\mathrm{Zn}$ and either Fe, $\mathrm{Cu}$, or Pd were also of interest because they also had significantly higher STYs than the unpromoted catalyst and obtained selectivities that were as good or slightly higher than the unpromoted catalysts. When considered in conjunction with the performance of the Fe and $\mathrm{Zn}$ individually promoted catalysts, further optimization of $\mathrm{Zn}, \mathrm{Fe}, \mathrm{Cu}$, and $\mathrm{Pd}$ promoters individually and $\mathrm{Fe}, \mathrm{Cu}$, and $\mathrm{Pd}$ in combination with $\mathrm{Zn}$ is warranted. 


\subsection{References}

Gerber MA, JF White, and DJ Stevens. 2007. Mixed Alcohol Synthesis Catalyst Screening. PNNL16763, Pacific Northwest National Laboratory, Richland, Washington.

Gerber MA, JF White, MJ Gray, and DJ Stevens. 2008. Evaluation of Promoters for Rhodium-Based Catalysts for Mixed Alcohol Synthesis. PNNL-17857, Pacific Northwest National Laboratory, Richland, Washington.

Gerber MA, MJ Gray, DJ Stevens, JF White, and BL Rummel. 2010. Optimization of Rhodium-Based Catalysts for Mixed Alcohol Synthesis -- 2009 Progress Report. PNNL-20115, Pacific Northwest National Laboratory, Richland, Washington. 



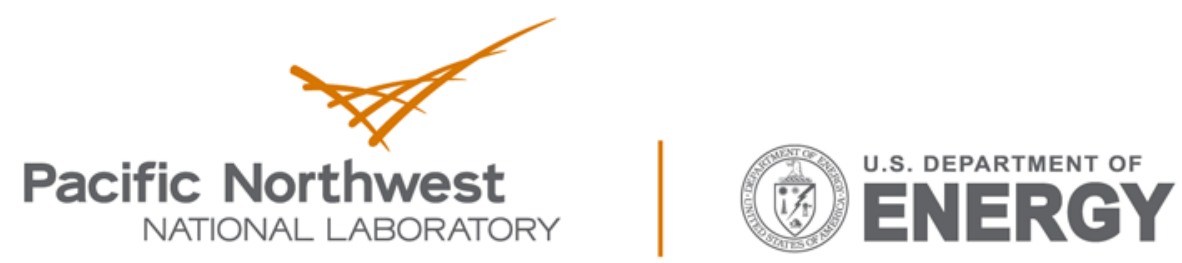

Proudly Operated by Battelle Since 1965

902 Battelle Boulevard

P.O. Box 999

Richland, WA 99352

1-888-375-PNNL (7665)

www.pnnl.gov 